\title{
Automation and the Displacement of Labor by Capital: Asset Pricing Theory and Empirical Evidence
}

\author{
JIŘÍ KNESL*
}

November 16, 2018

\begin{abstract}
I examine the asset pricing implications of technological innovations that allow capital to displace labor: automation. I develop a theory in which firms with high share of displaceable labor are negatively exposed to such technology shocks. In the model, firms optimally adopt technology to gain competitive advantage in the product market. Although automation increases an individual firm's competitive advantage, in equilibrium competition erodes profits and decreases firm value. Empirically, I develop a firm-level measure of displaceable labor share, based on detailed job classifications from the $\mathrm{O}^{*} \mathrm{NET}$ database, and find that firms with high displaceable labor share have negative exposure to technology shocks. A long-short portfolio sorted on this new measure is highly correlated with existing macroeconomic measures of technology shocks. Firms with negative exposure to these technology shocks earn a $4 \%$ per year return premium. The premium is positively predicted by decreases in the cost of capital goods. At the firm level, I confirm that a large negative exposure to technology shocks predicts lower employment and profitability following technology shocks, and these effects are amplified by higher within-industry competition.
\end{abstract}

JEL classification: G12, J24, O33.

*Knesl is at the Sauder School of Business, University of British Columbia (Oxford Saïd Business School from summer, 2019). I thank Adlai J. Fisher, Lorenzo Garlappi, Jan Bena, Murray Carlson, Carolin Pflueger, Markus Baldauf, Jack Favilukis, Jesse Perla, Boyan Jovanovic (discussant), Harald Uhlig, seminar participants at the University of Rochester, the University of California at San Diego, the University of Washington, University of Oxford, the University of Amsterdam, BI Norwegian Business School, Stockholm School of Economics/Swedish House of Finance and conference participants at the Belgrade Young Economists Conference 2019, IRMC 2019, Yale Doctoral Fall Finance Conference 2018, the Macro Financial Modeling Summer Session at the Becker Friedman Institute 2018, UBC Finance Summer Conference 2018 and FMA Doctoral Consortium 2018 for valuable comments. 
Technological advances over the last four decades have led to adoption of many new technologies 1 An important subset of these innovations, including for example robots and software, focus on automation that displaces human labor in favor of machine capital (see, e.g, Acemoglu and Restrepo (2017) and Autor, Levy, and Murnane (2003)). The massive adoption of such technologies by businesses, the associated large-scale displacement of routine-task labor, and the resulting societywide impacts have been termed "The Second Machine Age" (Brynjolfsson and McAfee, 2014). The importance of this wave of automation for the economy naturally raises the question of how automation has affected, and continues to affect, asset prices.

In this paper, I study whether firms' share of displaceable labor that can be automated by capital affects firms' value and their exposure to technology shocks. The amount of routine tasks which can be automated varies across occupations and thereby across industries 2 I find that firms with high share of displaceable labor have more negative exposure to technology shocks that facilitate automation. I demonstrate that a long-short portfolio of firms sorted on their share of displaceable labor replicates the dynamics of price changes in capital goods, thus creating a strong connection between a macroeconomic variable and the dynamics of stock returns. I further show that firms with a negative exposure to technology shocks earn an average return premium of $4 \%$ per year. The premium varies over time, being high in periods of strong technological progress, and is positively predicted by decreases in prices of capital goods. These properties of the premium are consistent with a compensation for households' time-varying job displacement risk.

To understand these findings, I develop a general equilibrium model of optimal technology adoption with heterogeneous firms that compete in product markets, and heterogeneous households that experience uninsurable idiosyncratic labor income shocks. In the model, all firms within a given industry have the same opportunity to adopt a technology. I show that a technology shock that facilitates automation decreases profits and market value of firms that can replace labor by capital. Although additional economic mechanism such as market entry, operating leverage or inability of firms to adopt new technology can deliver a similar result, this model points out that only a realistic assumption of product market competition is necessary to obtain this result. The model further highlights that the price of technology shocks depends on households' idiosyncratic labor income when some of the households are replaced by capital.

In the model, a technology shock embodied in capital allows firms to use cheaper capitalbased, instead of labor-based, production. Automation, which creates an optimal displacement of labor by capital, leads to a lower production cost but entails technology adoption cost. In a competitive environment, a firm's profit depends on its product price relative to the product prices of its competitors. As all firms in a given industry have the same share of displaceable labor, a symmetric Nash equilibrium of optimal automation exists. Because automation lowers a firm's product price relative to its competitors and increases its revenues, upon the occurrence of a technology shock each firm in the industry has an incentive to automate despite the technology

\footnotetext{
${ }^{1}$ See, e.g., Jovanovic and Rousseau (2005).

${ }^{2}$ See Autor and Dorn (2013). This paper provides similar results.
} 
adoption cost. These benefits deteriorate as the number of automated firms in the industry increases and lower product prices become the industry-wide standard. As a consequence, automation does not provide an advantage but is rather a costly necessity to stay competitive. I show that in equilibrium, technology shocks lead to lower firms' profits. Firms with a displaceable labor share have negative exposure to such technology shocks.

An appealing feature of the model is its flexibility to generate both positive and negative price of technology shocks. The sign of the price of risk depends on the dispersion of individual workers' future labor productivity. Technology shocks create risk for households. The adoption of capital-based production reallocates workers from old to new occupations. Although on average all workers will be more productive in their new occupations, individual workers experience either increase or decrease in their productivity. This labor productivity shocks are purely idiosyncratic and realized only once the worker moves to the new occupation. Since the occurrence of these idiosyncratic shocks is triggered by the aggregate technology shocks and markets are incomplete, the idiosyncratic risk affects the premium of the aggregate technology shock. If the dispersion of the individual labor productivity shocks is low, households do not fear technology shocks that facilitate automation and the technology shocks generate good states for households. If the dispersion of individual workers' productivity increases, households dislike technology shocks as some of them may lose parts of their labor income. This result highlights the importance of imperfect risk sharing as described in Constantinides and Duffie (1996) and its relationship to technological progress as described in Kogan, Papanikolaou, and Stoffman (2017), and Gârleanu and Panageas (2017).

Empirically, I measure a firm's share of displaceable labor by a ratio of labor that can be easily substituted by capital and the firm's current capital stock. To construct this measure, I classify employees' occupations by the routine intensity of their tasks using a comprehensive set of occupational characteristics from the O*NET database and merge the occupational level data with firm data for employment and capital stock from Compustat ${ }^{3}$ I find that the share of displaceable labor is predominantly an industry-level characteristic. The variation between industries explains $70 \%$ of the total cross-sectional variation in the share of displaceable labor.

I use changes in quality-adjusted relative prices of capital goods as an empirical measure of technology shocks 4 The theoretical foundation of this measure has been shown in previous literature (e.g., Cummins and Violante (2002); Hornstein and Krusell (1996)) and is based on the idea that improvements in the production of capital goods such as machines and software are reflected in lower prices of these goods adjusted for changes in quality. I empirically verify this assumption using data from the NBER-CES Manufacturing Industries database and the Input-Output Accounts from the U.S. Bureau of Economic Analysis (BEA) ${ }^{5}$ Decreases in quality-adjusted prices of capital

\footnotetext{
${ }^{3} \mathrm{O} * \mathrm{NET}$ database is currently the primary source of occupational information in the U.S. It provides a comprehensive and updated set of occupational characteristics such as required skills and abilities or importance of various activities and tasks. O*NET database is administered by the U.S. Department of Labor/Employment and Training Administration through the O*NET Resource Center. The predecessor of the O*NET database is the Dictionary of Occupational Titles whose data are incorporated in the first releases of the O*NET database.

${ }^{4}$ See Greenwood, Hercowitz, and Krusell (1997, 2000); Fisher (2006).

${ }^{5}$ NBER-CES Manufacturing Industries database from Becker, Gray, and Marvakov (2013) provides data on pro-
} 
goods are indeed associated with improvements in industries producing capital goods.

I first show that portfolios of firms sorted on their share of displaceable labor have large differences in their exposure to technology shocks. Firms with the highest share of displaceable labor have strongly negative exposure to technology shocks. The magnitude of the exposure decreases monotonically across the portfolios toward firms with low share of displaceable labor. A long-short portfolio based on this measure successfully approximates the time-series of technology shocks with a correlation of 0.6 and a strong overlap in all periods of large technology shocks. This result is present among both manufacturing and non-manufacturing firms. I show that the differences in the risk exposure to technology shocks are also not driven by firms' differential exposure to other risk factors.

Second, I investigate whether firms' risk exposure to technology shocks earns a return premium in the cross section of stocks. I first show that technology shocks measured by the changes in quality adjusted relative prices of capital are a state variable indicating the risk of labor income for households. Assets that co-move with this state variable are expected to earn a premium. I find that firms with strongly negative exposure earn a return premium of $4 \%$ per year. The average returns monotonically decrease across portfolios toward firms with weak risk exposure. Firms' size or growth opportunities might be related to firms' share of displaceable labor and correlate with the stock returns in the cross section. I first show that the Capital Asset Pricing Model (CAPM) and the size (SMB) and value (HML) factors do not explain the return premium. I next show that standard cross-sectional return predictors do not explain the return premium in firm-level panel regressions. I use conditional double sorts and show that the premium is also not driven by these return predictors in a non-linear way.

Third, I investigate the time variation and predictability of the return premium. If the estimated return premium is associated with labor income risk, it will follow a similar pattern over time. The labor income risk is high in states of high technology shocks when the prices of capital goods decrease. I find that the return premium is predictable by the changes in the prices of capital goods. Periods of positive technology shocks, which decrease the prices of capital goods, are associated with high return premium. In a companion paper (Knesl, 2018), I show that decreases in the prices of capital goods increase households' labor income risk and job displacement risk as cheaper and more productive capital substitutes for human labor. This evidence further rationalizes the return premium as a compensation of labor income risk.

Last, I examine whether firms with different exposure to technology shocks differ also in their behavior upon the occurrence of technology shock. Firm's differential behavior and financial performance following technology shocks provide a valuable indication for the underlying economic mechanism. I find that when the relative prices of capital goods decrease, firms with strongly negative exposure decrease employment and increase capital more than firms with weak exposure. These firms also experience large decrease in sales, return on capital and return on equity. This ev-

ductivity and other variables at a detailed industry level. The Input-Output Accounts from the BEA provide MAKE and USE tables that allow to categorize industries into industries producing capital and consumption goods. 
idence directly supports the conjecture that firms' risk exposure to technology shocks reflects firms' financial underperformance associated with changes in production technology following a technology shock. I document that these effects are stronger for firms in highly competitive industries, a finding that underlines the importance of product market competition.

In this paper, I contribute to two streams of literature. First, a recent literature has focused on the implications of technology shocks embodied in capital for firms' growth opportunities (e.g., Papanikolaou (2011); Kogan and Papanikolaou (2014); Kogan et al. (2017)), the pricing of crosssectional return anomalies (e.g., Kogan and Papanikolaou (2013); Garlappi and Song (2016)), and the relationship with market power (Garlappi and Song, 2017). While the general focus of these studies is on technological advances that increase the productivity of capital with limited effects on labor, I examine technology shocks where capital replaces labor. I show that these technology shocks are important for firms' adoption of labor-replacing technologies and drive households' job displacement risk ${ }^{6}$ A useful benefit of my approach is the construction of a zero-cost portfolio based on firms' displaceable labor share that highly correlates with a macroeconomic measure of technology shocks.

Second, I contribute to literature on the asset pricing when markets are incomplete, specifically by the inability to insure households' job displacement and labor income risk. The asset pricing implications of uninsurable idiosyncratic labor income or consumption risk on asset prices have been addressed in several earlier studies (e.g., Constantinides and Duffie (1996); Constantinides and Ghosh (2017); Schmidt (2016)). Recent papers examine the effects of technological growth in the presence of imperfect risk sharing (e.g., Gârleanu, Kogan, and Panageas (2012); Gârleanu and Panageas (2017)). Using overlapping generations models, these papers show that although innovations can especially benefit new generations of agents, innovations have an important displacement effect if the benefits and risk cannot be shared within or across generations of agents. I adopt this attractive feature of technological innovation creating displacement risk, but I directly model job displacement as arising from capital displacing human workers in their occupations. Empirically, I show that the time-varying and predictable return premium of technology shocks that facilitate automation is consistent with time-varying job displacement risk that is driven by automation. This finding underlines the importance of state-dependent displacement risk as the singular element in this stream of literature.

A particular aspect of my paper, the riskiness of firms with displaceable labor, has been studied in a recent paper by Zhang (2018). He suggests that routine labor lowers firms riskiness by providing a real option hedge. In his empirical analysis, firms with a higher routine labor share relative to industry average have lower expected returns. I arrive at a different conclusion that is supported both by my theory and empirical evidence. The theoretical difference arises due to three main factors. First, differently from Zhang's partial equilibrium setting that focuses exclusively on a single firm's riskiness, I develop a general equilibrium model to examine how the process of automation

\footnotetext{
${ }^{6}$ An important aspect of my model is technology adoption, which has been studied in different settings in e.g., Pástor and Veronesi (2009), Atkeson and Kehoe (2007), Greenwood and Jovanovic (1999), and Hobijn and Jovanovic (2001).
} 
is priced on capital markets by creating risk for both firms and households. This highlights the link between automation and job displacement risk that is important to understand the pricing of automation on capital markets and the time-series properties of the return premium. Second, my model includes product market competition, whose relevance is supported empirically but not considered in Zhang's model. Third, I explicitly show that firms' decision to displace labor by capital is directly related to prices of capital goods. I support all these features by empirical evidence. To reconcile the empirical differences between our papers, one has to consider that I use firms' share of displaceable labor relative to capital, a variable that varies primarily between industries, while Zhang examines a firm's deviation in routine labor share from an industry average 7 To the best my knowledge, I am the first to show how the automation process is priced on capital markets by affecting both firms and households. The key part of this is to document the strong co-movement between changes in prices of capital goods and returns of stocks sorted by the share of displaceable labor.

This paper relates to several other streams of literature. Many of these papers study the relationship between asset prices and different aspects of labor. Wage rigidities and operating leverage have been addressed in Chen, Kacperczyk, and Ortiz-Molina (2011), and Favilukis and Lin 2015, 2016). Organization capital stemming from the key talent and labor mobility have been studied in Eisfeldt and Papanikolaou (2013) and Donangelo (2014), respectively. Labor market frictions are examined in Belo, Lin, and Bazdresch (2014); Belo, Li, Lin, and Zhao (2017), and Kuehn, Simutin, and Wang (2017). Other studies examine industry competition (e.g., Hou and Robinson (2006); Loualiche et al. (2014); Corhay (2017); Bustamante and Donangelo (2017), and Corhay, Kung, and Schmid (2017)) and offshoring (e.g., Bretscher (2017)). The potential of capital to substitute some types of labor and complement others is at the center of many economic models that study the effects of technological change (e.g., Acemoglu and Autor (2011); Acemoglu and Restrepo (2018)) and more broadly (e.g., Zeira (1998); Krusell, Ohanian, Ríos-Rull, and Violante (2000).

The rest of the paper is organized as follows. In the next section, I develop a general equilibrium model of an optimal technology adoption that highlights how automation affects stock prices. Section [II provides the data sources, construction and validity of the measures of displaceable labor share and technology shocks. I examine the exposure to technology shocks of firms with different share of displaceable labor in section III. I describe the zero-cost portfolio that approximates the empirical measure of technology shocks in this section. Section IV documents the cross-sectional return premium and examines its properties including time-series predictability. This section also shows that firms' exposure to technology shocks is associated with differential investment and employment policies. I conclude in section $\mathrm{V}$.

\footnotetext{
${ }^{7}$ The percentage of the between-industry variation in the firms' share of displaceable labor depends on the particular industrial classification. I show in table 1 that $71.7 \%$ of variation in this variable is due to the between-industry variation when industries are defined at SIC 3-digit and NAICS 4-digit level.
} 


\section{The Model}

I develop a two-period general equilibrium model that provides a clear picture of how technology shocks affect asset prices through stimulating labor displacement and technology adoption. The model consists of two sectors with firms competing in monopolistic fashion and households supplying sector specific labor. Technology shocks decrease the price of capital and motivate firms to automate by adopting capital-based production. The model shows firms' optimal decision to adopt the capital-based production and its effects on the composition and risk exposure of firms within a given sector as well as the effect on the income of households supplying labor to the sector.

\section{A. Firms, Technology, and Automation}

The economy exists for two periods. The production side of the economy consists of two sectors $s \in\{1,2\}$. Sector $s=1$ initially consists of labor-based firms and sector $s=2$ of capital-based firms. Firms in sector $s=1$ have an opportunity to automate by adopting capital-based production upon the occurrence of a technology shock in the second period as described in more detail in below.

Within each sector $s$, there are $N$ firms that produce firm-specific differentiated goods $Y_{f, s, t}$ at time $t$ and compete in monopolistic fashion. The number of firms is large enough so that each firm can abstract from the consequences of its choices for the sector level aggregates. Firms produce their goods using either a labor-based, $Y_{f, s, t}^{l}=L_{f, s, t}$, or a capital-based linear production function, $Y_{f, s, t}^{k}=K_{f, s, t}$. A firm with capital-based production buys sector-specific capital $K_{f, s, t}$ at price $P_{s, t}^{I}$. I assume that firm's capital is active and fully depreciates in the period of investment. The cash flow of a capital-based firm is

$$
C F_{f, s, t}^{k}=P_{f, s, t}^{k} Y_{f, s, t}^{k}-P_{s, t}^{I} K_{f, s, t}
$$

where $P_{f, s, t}^{k}$ denotes the price of firm-specific good produced in a capital-based production. A firm with labor-based production hires sector-specific labor $L_{f, s, t}$ at sector-specific wage $W_{s, t}$. Laborbased firms have an option to automate by adopting capital-based production and paying automation cost $\kappa$. Firms will optimally do so when the price of capital investment $P_{s, t}^{I}$ becomes low enough. The cash flow of a firm with labor-based production is

$$
\begin{aligned}
& C F_{f, s, t}^{l}=P_{f, s, t}^{l} Y_{f, s, t}^{l}-W_{s, t} L_{f, s, t} \quad \text { if not automated } \\
& C F_{f, s, t}^{k}=P_{f, s, t}^{k} Y_{f, s, t}^{k}-P_{s, t}^{I} K_{f, s, t}-\kappa \quad \text { if automated }
\end{aligned}
$$

where $P_{f, s, t}^{l}$ and $P_{f, s, t}^{k}$ are the prices of the firm-specific good.

Sector-specific capital, $K_{s, t}$, is produced completely competitively in a linear production function with an aggregate technology level $A_{t}$ and sector-specific labor $L_{s, t}^{k}$ that is employed in producing capital:

$$
K_{s, t}=A_{t} L_{s, t}^{k}
$$

I further assume that installation of capital is subject to decreasing returns to scale at the total 
amount of sector-specific capital as described in equation 4. The assumption of strictly decreasing returns to scale $0<\alpha<1$ is important for the existence of a mixed-strategy equilibrium described below, but not for the final implications for stock returns 8

$$
I_{s, t}=K_{s, t}^{\alpha} \quad \text { where } \quad I_{s, t}=\sum_{f=1}^{N} K_{f, s, t}
$$

Hence capital production and installation imply that individual firms face the following price of capital:

$$
P_{s, t}^{I}=\frac{1}{A_{t}} W_{s, t} I_{s, t}^{\frac{1-\alpha}{\alpha}} \frac{1}{\alpha}
$$

Equation 5 shows that an increase in technology $A_{t}$ decreases the effective price of capital investment. This effect is partially offset by higher sector-level investment if $\alpha<1$. The technology $A_{t}$ and the total amount of sector-specific investment determine the marginal cost of capital-based production relative to the marginal cost of labor-based production. Automation becomes favorable when the marginal cost of capital-based production decreases relative to the marginal cost of labor-based production.

In the first period, sector $s=1$ consists of firms that use labor-based production and have the option to automate. Sector $s=2$ consists entirely of firms that already use capital-based production. The level of technology $A_{t}$ is subject to a technology shock that is realized at the beginning of the second period. A technology shock increases the level of technology $A_{t}$. Specifically, I assume an initial level of technology $A^{\text {Low }}$ that can increase to $A^{H i g h}$ with probability $p_{H}$ as described in 6 ,

$$
A_{1}=A^{\text {Low }}, \quad A_{2}= \begin{cases}A^{\text {Low }}, & \text { with probability } 1-p_{H} \\ A^{\text {High }}, & \text { with probability } p_{H}\end{cases}
$$

A technology shock $A^{\text {Low }} \rightarrow A^{\text {High }}$ decreases the price of capital investment $P_{s, 2}^{I}$ in both sectors $s=1,2$. The assumption of constant or decreasing prices of capital investment is supported by the empirical evidence as the quality adjusted relative prices of capital goods experienced a secular decrease over the last four decades (see, Fisher (2006); Cummins and Violante (2002) ? $^{9}$

The firm-specific goods are combined to sector-specific goods using a constant elasticity of substitution (CES) function:

$$
Y_{s, t}=\left(\sum_{f=1}^{2} Y_{f, s, t}^{\frac{\nu-1}{\nu}}\right)^{\frac{\nu}{\nu-1}}
$$

where $\nu$ is the elasticity of substitution between the firm-specific goods. I assume $\nu>1$ which

\footnotetext{
${ }^{8}$ The assumption of decreasing returns to scale for installation of capital at the sector level implies that individual firms do not internalize the effect of their capital investment on the marginal cost of capital investment. It further implies that the amount of capital used in a sector is always equal or greater than the sum of capital investments of individual firms. This assumption is equivalent to adjustment or installation cost of capital at the sector level.

${ }^{9} \mathrm{I}$ document an average decrease in quality adjusted relative prices of capital goods of 4 percent per year since 1960 (see, table IA.10
} 
implies that the firm-specific goods are imperfect substitutes to each other. The prices of the sector-specific goods can be expressed as

$$
P_{s, t}=\left(\sum_{f=1}^{N} P_{f, s, t}^{1-\nu}\right)^{\frac{1}{1-\nu}} .
$$

The sector goods are combined to an aggregate final consumption good using a CES function with a different elasticity of substitution, $\mathrm{f}^{10}$

$$
Y_{C, t}=\left(\sum_{s=1}^{2} Y_{s, t}^{\frac{\rho-1}{\rho}}\right)^{\frac{\rho}{\rho-1}} .
$$

I choose the aggregate consumption goods as a numeraire by setting its price $P_{C, t} \equiv 1$, and assume that $\frac{\nu-1}{\nu}>\frac{\rho-1}{\rho}$. This assumption implies that firm-specific goods within a given sector are closer substitutes than sector-specific goods. For example, individual products in food industry substitute each other more readily than all food products substitute products of a different industry such as paper mills.

Firms within each sector compete in a monopolistic fashion. Given the production type, firms maximize dividends by setting the price of their goods:

$$
\begin{gathered}
D_{f, s, t}^{l}=\max _{P_{f, s, t}^{l}}\left\{P_{f, s, t}^{l} Y_{f, s, t}^{l}-W_{s, t} L_{f, s, t}\right\} \quad \text { where } \quad Y_{f, s, t}^{l}=\left(\frac{P_{f, s, t}^{l}}{P_{s, t}}\right)^{-\nu} Y_{s, t} \\
D_{f, s, t}^{k}=\max _{P_{f, s, t}^{k}}\left\{P_{f, s, t}^{k} K_{f, s, t}-P_{s, t}^{I} K_{f, s, t}\right\} \quad \text { where } \quad Y_{f, s, t}^{k}=\left(\frac{P_{f, s, t}^{k}}{P_{s, t}}\right)^{-\nu} Y_{s, t},
\end{gathered}
$$

where $Y_{f, s, t}^{l}$ and $Y_{f, s, t}^{k}$ are the demand functions for the firms' goods. The first order conditions of firms' optimization in 10 and 11 imply that firms charge constant mark-ups over the marginal production cost:

$$
P_{f, s, t}^{l}=\frac{\nu}{1-\nu} W_{s, t} \quad \text { and } \quad P_{f, s, t}^{k}=\frac{\nu}{1-\nu} P_{s, t}^{I} .
$$

Upon the realization of the technology shocks at the beginning of $t=2$, firms in the labor-based sector $s=1$ decide whether to automate the production. Automation changes the labor-based production to capital-based production by incurring automation cost $\kappa$ :

$$
D_{f, 1,2}=\max \left\{D_{f, 1,2}^{l}, D_{f, 1,2}^{k}-\kappa\right\}
$$

Automation changes the firm composition as well as the use of labor within the sector within the sector $s=1 . \delta=\frac{\sum_{f=1}^{N} \mathbb{1}\{\text { Automate }=\text { Yes }\}_{f}}{N}$ denotes the percentage of firms in sector $s=1$ that decide to automate. Automation shifts labor from the direct production of firms' goods to the production

\footnotetext{
${ }^{10}$ An equivalent aggregation can be achieved when the sector-specific goods are consumed directly by households with CES preferences and elasticity of substitution $\rho$.
} 
of the sector-specific capital. $L_{1,2}^{l}=\sum_{f=1}^{N} L_{f, 1,2} \mathbb{1}\{\text { Automate }=N o\}_{f}$ is sector $1^{\prime} s$ labor that is employed directly in labor-based firms. $L_{1,2}^{k}=\frac{1}{A_{2}}\left(\sum_{f=1}^{N} K_{f, 1,2} \mathbb{1}\{\text { Automate }=Y e s\}_{f}\right)^{\frac{1}{\alpha}}$ is sector $1^{\prime} s$ labor that is employed in the production of the sector-specific capital. The total amount of labor in sector $s=1$ is $L_{1,2}=L_{1,2}^{l}+L_{1,2}^{k}$.

\section{B. Households}

There is a large number, $N_{h}$, of ex-ante identical households. Each household consists of two spouses, each of which supplies labor effort to a different sector. Households derive utility from consumption $c_{h, t}$ and disutility from labor effort $H_{h, 1, t}$ and $H_{h, 2, t}$ according to a utility function in the spirit of Greenwood, Hercowitz, and Huffman (1988):

$$
U\left(c_{h}, H_{h, 1}, H_{h, 2}\right)=\mathbb{E}\left[\sum_{\tau=t}^{2} \beta^{\tau-t} \frac{\left(c_{h, \tau}-\chi \frac{H_{h, 1, \tau}^{1+\theta}}{1+\theta}-\chi \frac{H_{h, 2, \tau}^{1+\theta}}{1+\theta}\right)^{1-\gamma}}{1-\gamma}\right],
$$

where $\beta$ is households' subjective discount factor, $\chi$ governs the disutility of labor effort, $\gamma$ is the coefficient of risk aversion, and $\frac{1}{\theta}$ is the Frisch elasticity of labor supply.

Now I introduce an idiosyncratic labor productivity risk. The labor effort $H_{h, s, t}$ transforms to $L_{h, s, t}=H_{h, s, t}$ effective hours of labor unless the spouse shifts from working directly in a laborbased firm to working in the production of sector-specific capital. If the spouse has to move to the production of sector-specific capital, the labor effort transforms to $L_{h, 1,2}=\left(1+\tilde{\epsilon}_{h}\right) H_{h, 1,2}$ effective hours of labor. $\tilde{\epsilon}_{h}$ is the spouses' idiosyncratic random variable that determines their labor productivity when they move to the new job. It is important to mention that the job movements are purely intra-sectoral. When firms in sector $s=1$ automate by adopting capital-based production, a corresponding number of spouses will be displaced from these firms and employed in the production of sector-specific capital within the same sector $s=1$. The spouses cannot observe their idiosyncratic labor productivity $\tilde{\epsilon}_{h}$ until they are employed in the new job. I specify the distribution of the idiosyncratic labor productivity by:

$$
\tilde{\epsilon}_{h}=\left\{\begin{array}{lll}
-\epsilon & \text { with probability } & p_{\epsilon} \\
+\epsilon & \text { with probability } & 1-p_{\epsilon}
\end{array} \text { where } \epsilon>0 .\right.
$$

It is important to emphasize that markets are incomplete in the sense that households cannot trade an asset that would insure them against the realization of the idiosyncratic labor productivity. This setup is analogous to Constantinides and Duffie (1996).

To maximize their utility, each household solves following problem:

$$
\max _{c_{h, t}, H_{h, 1, t}, H_{h, 2, t}} U\left(c_{h, t}, H_{h, 1, t}, H_{h, 2, t}\right) \quad \text { s.t. } \quad c_{h, t}=D_{h, t}+L_{h, 1, t} W_{1, t}+L_{h, 2, t} W_{2, t}
$$


where $D_{h, t}=\frac{1}{N_{h}}\left(\sum_{f=1}^{N} D_{f, 1, t}+\sum_{f=1}^{N} D_{f, 2, t}\right)$ is the households capital income. The specific form of the utility function 14 ensures that households do not take the wealth effect of the idiosyncratic labor productivity shock $\tilde{\epsilon}_{h}$ into account when they decide the optimal labor supply. The first order condition determines the optimal labor effort as:

$$
H_{h, s, t}=\left(\frac{W_{s, t}}{\chi}\right)^{\frac{1}{\theta}} \quad s \in\{1,2\} .
$$

The total supply of labor to sector $s$ at time $t$ is $L_{s, t}=\sum_{h=1}^{N_{h}} L_{h, s, t}$. The symmetry of the distribution of $\tilde{\epsilon}_{h}$ ensures that the labor effort of spouses working in capital production in sector $s=1$ at $t=2$ is transformed to effective hours on average in the same way as the labor effort of spouses working directly in labor-based firms in the same sector, $\mathbf{E}\left[L_{h, 1,2}\right]=\mathbf{E}\left[\left(1+\tilde{\epsilon}_{h}\right) H_{h, 1,2}\right]=H_{h, 1,2}$.

The utility optimization gives a household-specific stochastic discount factor of the form:

$$
\Lambda_{h}=\beta\left(\frac{c_{h, 2}-\chi \frac{H_{h, 1,2}^{1+\theta}}{1+\theta}-\chi \frac{H_{h, 2,2}^{1+\theta}}{1+\theta}}{c_{h, 1}-\chi \frac{H_{h, 1,1}^{1+\theta}}{1+\theta}-\chi \frac{H_{h, 2,1}^{1+\theta}}{1+\theta}}\right)^{-\gamma},
$$

Since all households are identical ex ante, the stochastic discount factors are identical across all households. Each single household prices assets in the same way. At the same time, aggregate consumption and labor efforts are not sufficient statistics for pricing firms as they omit the idiosyncratic component of households consumption due to the realization of the idiosyncratic labor productivity shock.

\section{Valuation}

The value of firms in labor-based sector $s=1$ at $t=1$ is given by:

$$
V_{f, s, 1}^{l}=D_{f, s, 1}^{l}+\mathbf{E}\left[\Lambda_{h} D_{f, s, 2}\right]
$$

The value of firms in the capital-based sector $s=2$ is defined equivalently as:

$$
V_{f, s, 1}^{k}=D_{f, s, 1}^{k}+\mathbf{E}\left[\Lambda_{h} D_{f, s, 2}^{k}\right]
$$

The expectation operator in the valuation equations 19 and 20 is defined from household $h^{\prime} s$ perspective over both aggregate and idiosyncratic states. The realization of all states and the corresponding probabilities are depicted in figure 1. It is important to note that the stochastic discount factor $\Lambda_{h}$ takes a different value in each possible realization including the realization of idiosyncratic labor productivity risk $\tilde{\epsilon}_{h}$. Hence the households' idiosyncratic risk affects the valuation of assets. The idiosyncratic risk is relevant only when $A^{\text {High }}$ is realized. The importance of the idiosyncratic risk is then given by the percentage of firms that automate $\delta^{*}$. Hence the idiosyncratic risk is state dependent as in Constantinides and Ghosh (2017). 


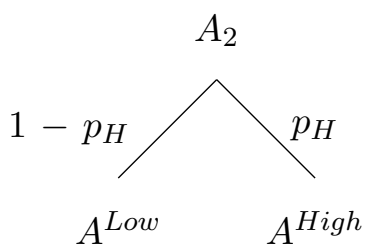

Firm composition

in sector 1
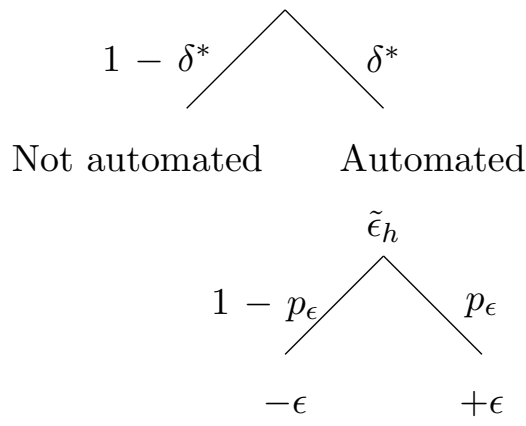

Figure 1. Households' Possible States.

\section{Equilibria}

The equilibrium is defined by the solution of the households' optimization problem 16, firms' optimization 10, 11, and 13 and market clearing conditions on all markets. The market clearing conditions for product markets at the level of firms and sectors as well as for capital and labor markets are stated in appendix A.

In the second period, $t=2$, there is a further condition for a Nash-type equilibrium for the equilibrium percentage $\delta^{*}$ of firms that automate within sector $s=1$. Each firm must prefer its choice of the production type given the choices of the remaining firms in the sector. There is a unique equilibrium of one of the following three types.

Equilibrium 1. None of the firms in the sector prefers capital-based production, $\delta^{*}=0$. The sector remains homogeneous with labor-based firms only. In this equilibrium, inequality 21 a holds. The left-hand side shows the payoff when the firm switches to capital-based production. This payoff consists of dividends and an automation cost. The right-hand side is the dividend of a firm that keeps labor-based production. If the price of capital is high enough, no firm will have an incentive to automate as it leads to lower sales and requires automation cost $\kappa 11$

\footnotetext{
${ }^{11}$ This reasoning abstracts from the effects on the sector level variables.
} 


$$
\begin{gathered}
\text { a. } \quad \nu P_{f, 1,2}^{k}\left(\frac{P_{f, 1,2}^{k}}{P_{1,2}\left(\delta^{*}\right)}\right)^{-\nu} Y_{1,2}\left(\delta^{*}\right)-\kappa \leq \nu P_{f, 1,2}^{l}\left(\frac{P_{f, 1,2}^{l}}{P_{1,2}\left(\delta^{*}\right)}\right)^{-\nu} Y_{1,2}\left(\delta^{*}\right), \quad \delta^{*}=0 \\
\text { b. } \quad \nu P_{f, 1,2}^{k}\left(\frac{P_{f, 1,2}^{k}}{P_{1,2}\left(\delta^{*}\right)}\right)^{-\nu} Y_{1,2}\left(\delta^{*}\right)-\kappa=P_{f, 1,2}^{l}\left(\frac{P_{f, 1,2}^{l}}{P_{1,2}\left(\delta^{*}\right)}\right)^{-\nu} Y_{1,2}\left(\delta^{*}\right), \quad 0<\delta^{*}<1 \\
\text { c. } \nu P_{f, 1,2}^{k}\left(\frac{P_{f, 1,2}^{k}}{P_{1,2}\left(\delta^{*}\right)}\right)^{-\nu} Y_{1,2}\left(\delta^{*}\right)-\kappa \geq \nu P_{f, 1,2}^{l}\left(\frac{P_{f, 1,2}^{l}}{P_{1,2}\left(\delta^{*}\right)}\right)^{-\nu} Y_{1,2}\left(\delta^{*}\right), \quad \delta^{*}=1, \\
\text { where } \quad P_{1,2}\left(\delta^{*}\right)=\left(P_{f, 1,2}^{k}{ }^{1-\nu} \delta^{*} N+P_{f, 1,2}^{l}{ }^{1-\nu}\left(1-\delta^{*}\right) N\right)^{\frac{1}{1-\nu}} \\
\text { e. } Y_{1,2}\left(\delta^{*}\right)=\left(Y_{f, 1,2}^{k}{ }^{\frac{\nu-1}{\nu}} \delta^{*} N+Y_{f, 1,2}^{l}{ }^{\frac{\nu-1}{\nu}}\left(1-\delta^{*}\right) N\right)^{\frac{\nu}{\nu-1}}
\end{gathered}
$$

This equilibrium is shown in the first column (no shock) in figure 2, Panel A shows the marketclearing prices of goods produced by each type of firm, labor-based and automated, as a function of the percentage of firms that automate $\delta$. The blue line depicts the prices of goods produced by labor-based firms and the red line depicts the equivalent function for automated firms. I select the model parameters so that the lines intersect at $\delta=0$ if the technology $A_{2}$ remains constant at $A^{\text {Low }}$. The goods prices of automated firms are predominantly increasing in $\delta$. The increase reflects the decreasing returns to scale of the capital installation function 4.

\section{[Place Figure 2 about here]}

Panel B shows the corresponding demands for the goods of each firm type as functions of $\delta$. The demand for goods of labor-based firms is above the demand for goods of automated firms for $\delta>0$ as the prices of labor-based firms' goods are lower in this region. This follows from the demand functions in equations 10 and 11 .

Panel C shows the dividends of each type of firm as functions of $\delta$. The dividends of labor-based firms are above the dividends before automation cost of automated firms for $\delta>0$. This follows from the price elasticity of the demand functions for firm-specific goods $-\nu<-1$. The dividends of automated firms are even smaller when the automation cost $\kappa$ is taken into account. Hence the equilibrium percentage of automated firms in sector $s=1$ is $\delta^{*}=0$.

Equilibrium 2. A percentage $0<\delta^{*}<1$ of firms in the sector automates and pays automation cost. This equilibrium can be thought of as a mixed-strategy equilibrium where firms choose an optimal probability $\delta^{*}$ to automate and probability $1-\delta^{*}$ to keep the labor-based production. The equilibrium is defined by the equality $21 \mathrm{~b}$. The left-hand side shows the payoff of a firm that automates. The right-hand side is the dividend of a firm that keeps labor-based production. Abstracting from the effects at the sector level, the equality holds when the gain from higher sales due to lower goods prices $\left(\frac{P_{f, 1,2}^{k}}{P_{1,2}\left(\delta^{*}\right)}\right)^{-\nu}$ exactly counterweights the automation cost $\kappa$. Firms that 
adopt capital-based production extract higher rents at the cost of firms that keep labor-based production.

The middle column of figure 2 shows this type of equilibria. I assume an incremental improvement in the technology level $A^{\text {High }}$. In panel $\mathrm{A}$, the prices of goods from automated firms shift downward and intersect the price function of the labor-based firms. Panel B shows that the changes in prices lead to a higher demand for goods of automated firms relative to labor-based firms if the percentage of automated firms is low enough. Panel C shows the equilibrium percentage of firms $\delta^{*}$ in sector $s=1$ that optimally automate production. In the region $\delta<\delta^{*}$, labor-based firms have an incentive to automate as they will benefit from higher demand. In the region $\delta^{*}<\delta<\hat{\delta}$, firms do not want to automate as the slightly higher demand for their products does not compensate the automation $\operatorname{cost} \kappa$. In the region $\delta^{*}<\delta$, the demand for goods of automated firms is already below the demand for goods of labor-based firms. Firms are indifferent between keeping the labor-based production and automation only at $\delta^{*}$.

Equilibrium 3. All firms in the sector automate, $\delta^{*}=1$. The sector is homogeneous with capital-based firms only, and inequality 21 c holds. This equilibrium arises when the price of capital $P_{1,2}^{I}$ is low enough. In this case, a firm will experience dramatically lower sales when it keeps the labor-based production given all other firms have automated. Hence all firms optimally adopt the capital-based production despite the automation cost to avoid more severe punishment through lower sales. Abstracting from the effects at the industry level, all firms keep the same rent but pay the automation cost $\kappa$.

This equilibrium is shown in the right-hand side column in figure 2. I assume a large increase in the technology level $A^{\text {High }}$. In this case the prices of goods of automated firms are always below the prices of labor-based firms. This is reflected in the demand function of the automated firms that is always above the demand function of the labor-based firms. If the improvement in the technology level $A_{2}$ is large enough, the net dividend of automated firms will be above the dividend of labor-based firms regardless of the percentage of automated firms in the sector. The equilibrium percentage of automated firms is $\delta^{*}=1$. Even in this case the net dividend can be below the original level. All firms in the sector optimally decide to automate even if automation leads to a lower net dividend. Firms which had stuck with the labor-based production would have experienced much lower revenues that is more penalizing than the automation cost $\kappa$. This situation highlights that adopting a relatively cheaper production technology can become a pure necessity to stay competitive and the automation benefits are passed to the final consumers in the form of lower product prices.

Panel A in figure 3 presents the relationship between the magnitude of the technology shock $A^{\text {High }}$, conditional on the occurrence of this state, and the equilibrium percentage of automated firms $\delta^{*}$. This relationship is strictly positive. A higher level of technology $A^{\text {High }}$ decreases the prices of capital investment $P_{1,2}^{I}$ and makes capital-based production more favorable despite a higher amount of invested capital $I_{1,2}$. I select the model parameters such that the first type of equilibria, $\delta^{*}=0$, exists when $A_{2}=A^{\text {Low }}<0.85$. The second type of equilibria, $0<\delta^{*}<1$ emerges when 
$A_{2}=A^{\text {High }}$ and $0.85<A^{\text {High }}<1.06$. The third type of equilibria, $\delta^{*}=1$ establishes if the technological change is large enough, $A_{2}=A^{\text {High }}>1.06$.

\section{E. Implications for Firms Risk Exposure and the Dynamics of Stock Returns}

In this section I show that a positive technology shock that facilitates automation can lead to an adverse outcome for firms in a sector that is undergoing at least partial automation. The adverse effect of such a shock is equally present among all firms within the sector regardless of whether the particular firm automates or not.

Panel B of figure 3 shows the equilibrium dividends of firms in sector $s=1$ as a function of the magnitude of the technology shock $A^{\text {High }}$, conditional on realization of this state. In equilibrium, the dividends are identical for all firms in the sector regardless of whether the particular firm automates or not. An increase in the technology shock leads to a lower dividend of every firm in this sector. This relationship is weak for low levels of $A^{\text {High }}$ but becomes stronger for higher values of the technology. This reflects the convex relationship between the equilibrium percentage of automated firms $\delta^{*}$ and $A^{\text {High }}$ shown in panel $\mathrm{A} 12$

A larger technology shock leads to a higher percentage of firms that automate $\delta^{*}$ and charge lower product prices. This decreases the price of the sector-aggregate good $P_{1,2}\left(\delta^{*}\right)$ as shown in formula $21 \mathrm{~d}$. Since firm's relative revenues depend on the price of its good relative to the sector-aggregate good $\left(\frac{P_{f, 1,2}}{P_{1,2}\left(\delta^{*}\right)}\right)^{-\nu}$ with $\nu>1$, it becomes more prohibitive to keep the labor-based production that produces goods at higher relative prices. At the same time, the rents of automated firms decrease as the prices of their goods and the price of the sector-aggregate good come closer to each other. Automation becomes a costly necessity to stay competitive 13

\section{[Place Figure 3 about here]}

Panel $\mathrm{C}$ shows the effect of technology shocks on dividends of firms in sector $s=2$. This relationship is strictly positive. Since this sector already consists of firms with capital-based production, firms do not undergo the costly process of automation. Hence firms in sector $s=2$ benefit directly from lower prices of capital investment $P_{2,2}^{I}$ brought by a higher level of technology.

In this model, the effect of technology shock on dividends translates directly to firms' risk exposure to the shock. I plot the risk exposure of firms in each sector as functions of $A^{H i g h}$ in panel A of figure 4. Firms in sector $s=1$ have negative exposure to technology shocks. The magnitude of the exposure is low for low values of $A^{\text {High }}$ but increases dramatically. Hence a technology shock decreases the firm value of firms in this sector. These firms experience negative return on the impact of technology shock. Firms in sector $s=2$, which consists entirely of capital-based firms, have positive exposure and experience positive stock return upon the occurrence of technology shock.

\footnotetext{
${ }^{12}$ I plot the firms' dividends as a function of the equilibrium percentage of automated firms $\delta^{*}$ in online appendix figure IA.1 This relationship becomes generally linear.

${ }^{13}$ This statement abstracts from inter-sectoral demand shifts. The inter-sectoral demand shifts are considerably smaller as the sector-level goods are weaker substitutes.
} 


\section{[Place Figure 4 about here]}

The results in this section show that competition forces firms to undergo costly automation process although its benefits are passed through to the final consumers. Firms with labor that can be automated by capital then exhibit negative risk exposure to technology progress that facilitates such automation.

\section{F. Implications for Stock Return Premium}

In this section, I show that the differences in firms' exposure to technology shocks are associated with differences in expected stock returns as the risk of technology shocks is priced by the households.

First, I emphasize that the model is able to general both negative and positive premium for the risk of technology shock that facilitate automation. The sign of the premium is determined by the dispersion of the idiosyncratic labor productivity shock $\epsilon$ the households face upon the occurrence of technology shock and the associated possible job movement. Figure 5 shows the relationship between the dispersion of the idiosyncratic labor productivity $\epsilon$ and the risk premium of an asset $\mathbf{E}\left[R^{I}\right]-R_{f}$ that has $\beta=1$ exposure to the technology shock $A_{2}$. Households require a positive premium for this asset if the idiosyncratic labor productivity risk $\epsilon$ is low. In this case, the higher average labor productivity of spouses working in the capital production due to $A^{\text {High }}$ dominates the idiosyncratic labor productivity risk. As $\epsilon$ increases the idiosyncratic labor productivity risk dominates and the return premium becomes negative. In this case, households dislike the occurrence of technology shock as they may experience a severe decrease in their labor income. The same asset becomes valuable as it outperforms upon the occurrence of the technology shock.

\section{[Place Figure 5 about here]}

For the following analysis, I assume the case of negative premium. This assumption will align with the empirical evidence in later sections. The relativity of the return premium described in figure 5, however, highlights that the implications of technology shock for expected stock return depend on the particular economic environment, in this case the households' ability to stay productive in new occupations.

Panel B in figure 4 shows the expected stock returns of firms in each sector as functions of the magnitude of the technology improvement $A^{\text {High }}$. Firms in sector $s=1$ earn higher expected return than firms in sector $s=2$. This follows directly from the firms' exposure and the assumption of negative risk premium. Firms in sector $s=1$ have a negative exposure (see panel A) to a negatively priced risk which results in high expected returns. The positive exposure of firms in sector $s=2$ to the same risk leads to lower expected returns.

The difference in the expected returns between firms in sector $s=1$ and $s=2$ increases with the magnitude of $A^{\text {High }}$ as shown in panel C. This follows from the changes in the exposure of firms in sector $s=1$ as shown in panel A. The exposure of firms in sector $s=1$ becomes more negative 
as $A^{\text {High }}$ increases, while the exposure of firms in sector $s=2$ remains almost constant. The increasing differences in the exposure of firms in each sector lead to similarly increasing differences in expected return.

\section{Data}

\section{A. Measuring Firms' Share of Displaceable Labor, The Automation Potential}

The main input in my analysis is a measure of firms' share of displaceable labor, the $\underline{\text { Automation }}$ Potential (AP). I use the occupational characteristics from the O*Net database, the composition of labor force from Occupational Employment Statistics (OES) and the relative importance of labor and capital to calculate the AP measure at the firm level. The AP measures the relative importance of labor that can be easily replaced by capital.

I measure firm $j^{\prime} s$ AP at time $t$ as:

$$
A P_{j, t}=\ln \left(\frac{L_{j, t}^{\text {routine }}}{K_{j, t}}\right)
$$

The numerator of the AP formula, $L_{j, t}^{\text {routine }}$ measures the number of employees in routine intensive occupations, i.e. labor that can potentially be substituted by capital. To assess the relative importance of routine labor in the production process, I divide the labor by firms' capital.14 I carefully examine a range of alternative specifications of the AP formula and discuss them in detail below.

I measure the potential of replacing human workers by capital in each occupation by the $\underline{\mathbf{R}}$ outine Task Intensity measure (RTI). This measure was originally developed by Autor and Dorn (2013) and measures the importance of routine, abstract and manual tasks in each occupation. High RTI scores indicate high importance of routine tasks in a given occupation. Routine tasks are defined as tasks that can be accomplished by following a precise set of rules and potentially be executed by machines programmed to follow this set of rules 15 Low RTI scores indicate low importance of routine tasks and high importance of abstract and manual tasks, which cannot easily be performed by machines.

The original measure was calculated for 330 occupations based on data from the Dictionary of Occupational Titles (DOT) 1977. I develop a new and more detailed version of the RTI measure based on occupational characteristics from the majority of the O*NET database releases. I describe the structure and the data collection procedure of the $\mathrm{O}^{*} \mathrm{NET}$ database in appendix $\mathrm{B}$.

\footnotetext{
${ }^{14}$ The term production process is used widely in this context. It refers not only to physical production but also to all operations of a given firm including firms in service sectors that do not necessarily produce physical products.

15 Autor et al. (2003) developed the original underlying data for the RTI measure and define the routine tasks as follows: "In our usage, a task is "routine" if it can be accomplished by machines following explicit programmed rules. Many manual tasks that workers used to perform, such as monitoring the temperature of a steel finishing line or moving a windshield into place on an assembly line, fit this description. Because these tasks require methodical repetition of an unwavering procedure, they can be exhaustively specified with programmed instructions and performed by machines.'
} 
This approach significantly improves the RTI measure in several dimensions. First, I use multiple releases of the $\mathrm{O}^{*} \mathrm{NET}$ database, which allows the new RTI measure to capture the changes in the occupational characteristics within occupations over time. Technological progress and automation are likely to change the nature of some occupations over time. Autor et al. (2003) show that occupations that increased the use of computers significantly reduced the input of routine tasks and became more nonroutine ${ }^{16}$ This evidence stresses the importance to account for changes in occupational characteristics over time. Second, I calculate the RTI measure for a larger number and more detailed occupations. Depending on the release of the O*NET database, I calculate the RTI measure for 654-731 occupations ${ }^{17}$ Third, I use larger set of underlying occupational characteristics (30 instead of 5) to measure the importance of routine, abstract and manual task inputs. The wide range of the characteristics provides a robust measurement of the importance of each type of tasks. It allows for changes in task inputs within occupations to be easily detected over time as some occupations may change only one characteristic while keeping others constant. This approach also addresses a possible bias in selecting suitable characteristics to measure the importance of tasks inputs 18

To calculate the RTI measure, I select 30 occupational descriptors and group them into descriptors measuring abstract, routine and manual tasks. I report the full list of the descriptors including the corresponding scales of measurement in online appendix table IA.3. I calculate the routine, abstract and manual task inputs for each occupation by averaging the scores of the corresponding descriptors as follows

$$
\begin{aligned}
T_{o c c, t}^{j}= & \frac{1}{N_{j}} \sum_{i \in N_{j}} \text { Descriptor } r_{o c c, t, i} \\
& j \in\{\text { Routine, Manual, Abstract }\},
\end{aligned}
$$

where $T_{o c c, t}^{j}$ is the input of task $j$ in occupation occ at time $t$ and $N_{j}$ is the set of descriptors for $j^{\prime} s$ task input. Using the task inputs, I calculate the RTI for each occupation as

$$
R T I_{o c c, t}=\ln \left(T_{o c c, t}^{R}\right)-\ln \left(T_{o c c, t}^{M}\right)-\ln \left(T_{o c c, t}^{A}\right)
$$

Occupations with a high RTI score predominantly consist of routine tasks and hence have high potential to be automated by machines. Occupations with a low RTI score require strong input of abstract or manual tasks, such as critical thinking, active learning, negotiation or operating vehicles and hence cannot easily be automated. I report the summary statistics of the RTI scores

\footnotetext{
${ }^{16}$ I find supportive evidence for changes in the RTI measure within occupations in online appendix figure IA.3

${ }^{17} \mathrm{I}$ report the exact number of occupations in each $\mathrm{O}^{*} \mathrm{NET}$ release for which I calculate the RTI measure in table IA.2

Acemoglu and Autor (2011) also construct RTI measure based on the O*NET database version 14.0. The approach and the selection of the underlying descriptors is similar and my RTI measure strongly correlates with the RTI measure in this paper. The main distinction is that I utilize the updates of the O*NET database as well as the original data from the Dictionary of Occupational Titles included in the first releases of the O*NET database. This allows me to account for the changes within occupations over time and avoid carrying over possible measurement errors to other years.
} 
and the underlying task inputs at the level of occupations in online appendix table IA.4. To provide examples of the most routine and non-routine occupations, I list representative routine and nonroutine occupations in online appendix table IA.5. These occupations are selected to represent the typical occupations with low and high RTI scores ${ }^{19}$ It is important to note that the routine task intensity is not the same dimension as labor skill dimension. Routine occupations are generally concentrated in the middle skill-level occupations with average labor income (see e.g. Autor and Dorn (2013)) ${ }^{20}$

The AP measure can vary between industries, as well as across firms within the same industry. The majority of the variation, however, is at the between industry level. Table I reports the summary statistics and variance decomposition of the AP measure into within and between industry variation. Panel A shows that there is a considerable variation in the share of displaceable labor measured by the AP measure at the firm level across firms in all industries and the results in panel $\mathrm{B}$ show that similar variation is present also when firm level observations are aggregated at the industry level, i.e. variation between industries. Panel $\mathrm{C}$ then shows formally that the majority of the variation in the AP measure is due to between industry variation, as it accounts for about $70 \%$ of the total variance. This result indicates that the automation potential measured by the ratio of routine labor to capital is a predominantly industry-specific characteristic ${ }^{21}$ I list the industries with the lowest and highest automation potential, as defined by the AP measure in online appendix table IA.7. I establish the validity and robustness and discuss potential shortcomings of the new RTI measure in appendix C.

\section{[Place Table $\mathbf{I}$ about here]}

I next establish the relationship between the AP measure and two other potential measures. First, I use the total number of all employees instead of the total capital in the denominator of the AP measure, i.e. Routine intensity $j_{j, t}=\ln \left(\frac{L_{j, t}^{\text {routine }}}{L_{j, t}^{\text {total }}}\right)$. Second, I use the number of all employees instead of employees in routine occupations in the numerator. This measure is in essence a firm's labor intensity, i.e. Labor intensity $=\ln \left(\frac{L_{j, t}^{\text {total }}}{K_{j, t}}\right)$. These two measures are positively correlated with each other. Online appendix figure IA.2 shows that the correlation is strong except for the 1990s when the sample was inflated by a large number of new dot-com firms that lacked typical production facilities. The strong relationship between these two measures has re-established again since 2005 ${ }^{22}$ Due to this strong relationship, both measures sort firms and industries crosssectionally in a very comparable way in most of the years examined.

\footnotetext{
${ }^{19}$ Since the RTI score changes for each occupation over time, I select representative routine and non-routine occupations with high and low RTI score, respectively, in multiple years. Full lists and detailed descriptions of the most routine and nonroutine occupations in O*NET 98, O*NET 5.1 and O*NET 20.1 are in online appendix.

${ }^{20}$ Another interesting fact shown in Abis (2017) is the ongoing pervasion of computing technology and algorithmic trading relative to discretionary human-based trading in fund management industry.

${ }^{21}$ Although the majority of the variation in AP is at the industry level, there are still firms within the same industry that differ from the industry peers. The within industry variation in share of routine labor relative to industry peers has been studied by Zhang (2018).

${ }^{22}$ The pattern is robust to the use of RTI measures based on each O*NET or DOT data.
} 
I also examine the importance of different types of capital in the denominator of the AP measure. Specifically, I use only equipment or equipment and intellectual products and property instead of a firm's total capital to address a potential concern that the total capital of some firms is dominated by structures. I also account for the changes in the composition of equipment over time on the basis of the real stock of 64 different types of equipment 23 This addresses the potential concern that some industries significantly increased the real stock of equipment, such as ICT equipment, whose nominal prices decreased over time and hence the increase in real stock would not be reflected in firm's total nominal capital. None of these variations are essential for the subsequent analysis. The results in the following sections are robust to the use of these alternative AP measures and results based on alternative specifications of AP measure are available upon request.

\section{B. Financial Data}

I focus on common stocks of firms listed on NYSE, NASDAQ, and AMEX from 1970 to 2015 and use monthly data from the Center for Research in Security Prices (CRSP). To calculate the AP measure, I require the firms to have underlying data for the number of employees and total net capital in the Standard and Poor's Compustat database. I exclude financials SIC 6000-6799, utilities SIC 4900-4999, and public sector companies SIC $\geq 9000$. Hou, Xue, and Zhang (2017) find that the a large number of previously documented cross-sectional return anomalies are strongly driven by micro-cap stocks and these anomalies are hardly replicable when the sample excludes micro-cap stocks. To address this concern, I exclude small and illiquid stocks as well as stocks with short history from my sample. I describe the applied filters in detail in appendix $\mathrm{D}$. None of these filters are essential for the documented results. The final sample contains a total of 8,150 unique firms. I also redo my analysis on the basis of S\&P 500 stocks and find quantitatively and qualitatively very similar results. The results based on the constituents of S\&P 500 are presented in online appendix.

\section{Measuring Technology Shocks Embodied in Capital}

I measure the technology shocks embodied in capital by the changes in quality adjusted relative prices of investment goods. The formal theoretical validity of this measure has been derived in previous literature, e.g. Greenwood et al. (1997); Cummins and Violante (2002); Hornstein and Krusell (1996) (see appendix E for a parsimonious theoretical foundation based on these papers) ${ }^{24}$ The intuition behind the theoretical foundation of this measure is that investment-specific technology shocks allow for production of new capital goods, such as machines, software or equipment, at lower cost or higher quality. Hence the changes in the quality adjusted prices of capital goods relative to aggregate prices are informative about the technological progress. I construct the mea-

\footnotetext{
${ }^{23}$ I use the BEA classification for the different types of equipment.

${ }^{24}$ Various versions of these measure has been successfully used in previous studies focusing on the effects of the investment-specific technology shock on economic growth, e.g. Greenwood et al. (1997) and business cycle, e.g. Greenwood et al. (2000); Fisher (2006)
} 
sure of technology shocks embodied in capital (I-shock measure) by subtracting the log changes in the quality-adjusted prices of capital goods from the log changes in the aggregate price level. An increase in the I-shock measure indicates a positive technology shock and is associated with higher quality and/or lower prices of capital goods.

The underlying price indexes are from the U.S. Bureau of Economic Analysis (BEA). I measure the aggregate price level by the price index of the personal consumption expenditures for nondurable goods. The quality-adjusted prices of capital goods are based on the price index for private fixed investment in nonresidential equipment. This price index is a combination of price indexes of 25 different types of equipment. I use annual frequency for both time-series and calculate the I-shock measure from 1970 to 2015.

Since the I-shock measure is based on quality adjusted prices of capital goods, it is important to account for the changes in quality of goods in the underlying price indexes. The increase in the horsepower of cars and increases in the processing power and memory of computers over recent decades are prominent examples of large quality changes of goods. Ideally, quality-adjusted price indexes take the changes of quality into account and express the price per efficiency unit. Several earlier papers, e.g. Griliches (1961); Gordon (1990), point out the lack of an appropriate quality adjustment of the NIPA price indexes of equipment. The BEA has addressed the problem of quality adjustment over the last three decades and developed price indexes that account for quality changes using various techniques such as hedonic regressions 25 The price indexes of fast improving types of equipment such as computers and peripherals have used hedonic-based quality adjustments since the 1980s. I further account for possible quality changes by using the quality adjustment from Cummins and Violante (2002). This adjustment accounts for the measured quality difference in the underlying components of the price index of capital goods from Gordon (1990) until 1983 and extrapolates the adjustment to recent years.

Consistent with previous literature, e.g. Fisher (2006), I document a positive mean of the I-shock measure, indicating a secular trend of decreasing prices and increasing quality of capital goods. I provide a full set of summary statistics of the I-shock measure in online appendix table IA.10. The I-shock measure correlates strongly with the TFP shock of industries producing the capital goods. The correlation with TFP shock of industries producing consumption goods is practically zero. This result is in line with the theoretical foundation of this measure. The correlation with the aggregate TFP shock is negligible. This reflects the fact that industries producing the capital goods comprise a relatively small part of the U.S. economy. The I-shock measure has a positive correlation with the GDP growth. This is consistent with previous papers showing that prices of capital goods are an important driver of economic growth, Fisher (2006); Greenwood et al. (2000).

The dashed blue line in figure 6 plots the normalized time-series of the I-shock measure from 1970 to 201526 The most prominent and pervasive technology shock during this period was from

\footnotetext{
${ }^{25}$ Wasshausen, Moulton, et al. (2006) provide a brief overview of the use of hedonic methods by the BEA to measure real GDP; Fox and McCully (2016) provide detailed information about the price indexes for all types of equipment and discusses the quality adjustments employed by BEA.

${ }^{26}$ The solid red line is a factor mimicking portfolio that is describe in sections III
} 
1997 to 2001. During these years, the normalized I-shock measure recorded a cumulative increase of 5.71 standard deviations. This increase was driven mainly by a large drop in the quality-adjusted prices of information processing equipment. The prices of this equipment decreased by 40 percent, while the prices of personal expenditures for nondurables increased by 8 percent. Since information processing equipment accounted for one third of total private investment, the aggregate price index of capital goods decreased by 15 percent. The massive drop in the prices of information processing equipment can be tracked back to a significant productivity growth (TFP shock) in a single manufacturing industry. The electronic computer manufacturing industry recorded an increase in productivity of 216 percent. The remaining manufacturing industries, including consumption goods producers, experienced only moderate productivity growth of 5.33 percent ${ }^{27}$

I link all other major shocks in the I-shock measure to the differential productivity growth of a small number of capital goods producing industries in online appendix table IA.12 ${ }^{28}$ I show in online appendix table IA.12 that the whole time-series of the I-shock measure can be approximated by differential productivity growth of capital producing industries. This evidence provides validity to the theoretical foundation of the I-shock measure as an appropriate measure of technology shocks embodied in capital goods.

\section{I-shock as an Income State Variable}

I show in a companion paper Knesl (2018) that technology shocks embodied in capital, measured by the changes in relative prices of capital goods, are an important source of job displacement and labor income risk. Lower prices and higher quality of capital goods allow substituting capital for labor in occupations that have the potential to be automated. Hence, technology shocks embodied in capital are an important state variable indicating the risk in labor income of households. This result is broadly in line with other papers investigating the impact of innovation and technological progress on labor income, e.g. Kogan et al. (2017). I provide a concise illustration of this result below. I refer the reader to the papers mentioned above for detailed results.

Panel A of table $\mathrm{II}$ reports the results of regressing contemporaneous and future changes in personal income, private fixed investment in equipment and employment on the I-shock measure and aggregate productivity shock. Specifically, I estimate the regression of this form

$$
\frac{1}{K+1} \sum_{k=0}^{K} y_{t+k}-y_{t+k-1}=\alpha+\gamma_{I s h o c k} \times I \text { shock }_{t}+\gamma_{T F P} \times T F P_{t}+\epsilon_{t+k},
$$

where $y_{t}$ is the log level of nominal personal income, private fixed investment, or total nonfarm employees ${ }^{29}{ }^{2}$ shock $k_{t}$ is the I-shock measure representing the change from $t-1$ to $t$. The $T F P_{t}$ is the

\footnotetext{
${ }^{27}$ The calculations are based on the data from the NBER-CES Manufacturing Industries database Bartlesman and Gray (1996) and the Input-Output Accounts data from the U.S. Bureau of Economic Analysis

${ }^{20}$ See also Greenwood and Yorukoglu (1997) for a detailed discussion of the positive technology shock in 1974.

${ }^{29}$ I use nominal personal income to avoid a potential mechanical effect of deflating as the I-shock measure contains changes in prices of consumption goods in its numerator. The estimation results based on nominal personal income represent lower bound.
} 
change in the aggregate productivity over the same time period. I estimate the regression at annual frequency from 1970 to 2015 for time horizons $K=0,1$, and 2 . The results are robust to controlling for lagged dependent variable and alternative specifications. The first three columns show that a positive technology shock embodied in capital (I-shock) is associated with an immediate increase in investment in equipment that fades away in the subsequent years. The estimates in columns (4)-(6) indicate that the I-shock leads to a significantly lower employment in the first and second year after the shock. The last three columns then show that a positive I-shock is also associated with lower personal income growth.

\section{[Place Table II about here]}

Looking only at the aggregate average income growth can hide potentially important effect of technology shocks on individual personal income growth. To examine the effect of the I-shock on higher moments of cross-sectional distribution of individual income, I estimate the regression equation 25 with changes in the first three central moments of the cross-sectional distribution of individual income growth as the dependent variable using the data from Guvenen, Ozkan, and Song (2014) ${ }^{30}$ Panel B of table II presents the estimates. The first three columns verify that the I-shock has a negative effect on the average income growth as documented in panel A. Columns (4)-(6) show the standard deviation increases only slightly following a positive I-shock. The last three columns show that a decrease in prices of capital goods, a positive technology shock, has the most negative effect on the skewness of individual income growth. A positive technology shock embodied in capital significantly increases the left skewness of the income growth distribution. Individuals are more likely to experience large drops in personal income in years following a positive I-shock.

This result is in line with Knesl (2018) in showing that a positive I-shock increases the probability of losing job. Large negative idiosyncratic shocks to income growth such as job loss are then pronounced in higher moments of income growth distribution as shown above. This support the assumption of the state dependent idiosyncratic labor productivity risk in the theoretical model presented earlier. Higher moments of the cross-sectional distribution of individual income growth play a central role in pricing assets in incomplete markets when agents face uninsurable income risk. Constantinides and Duffie (1996) derive a theoretical model of incomplete markets with heterogeneous agents and uninsurable idiosyncratic income risk where the second moment of the cross-sectional distribution of individual labor income enters the stochastic discount factor. Constantinides and Ghosh (2017) show that the third central moment of individual income growth drives asset prices and risk-free rate ${ }^{31}$ Schmidt (2016) provides evidence that the idiosyncratic tail risk of income growth is state-dependent and predicts stock returns, and further shows that a model with state-dependent, time-varying idiosyncratic disaster risk and incomplete markets matches the

\footnotetext{
${ }^{30}$ Estimating the regression equation $\sqrt{25}$ with levels of the central moments as dependent variables provides similar results. The results are similar when I control for lagged dependent variable.

${ }^{31}$ The theoretical model in Constantinides and Ghosh (2017) assumes that households consumption equals households labor plus dividend income, where the labor income is subject to uninsurable idiosyncratic shock. The model is estimated using individual consumption data from the Consumer Expenditure Survey
} 
key asset pricing moments.

\section{Technology Shocks and Displaceable Labor}

\section{A. Co-movement}

I sort stocks into five portfolios based on their share of displaceable labor (AP) to examine the time-series and cross-sectional properties of stock returns associated with firms' automation potential. I report the summary statistics of firm characteristics in each portfolio in online appendix table IA.15. The first portfolio consists of stocks with the highest AP. These firms also have high average labor intensity and a high percentage of employees in routine occupations. The average AP measure then decreases from -2.9 in the first portfolio to -5.9 in the fifth portfolio. The portfolios are rebalanced annually at the end of June and portfolio returns are value-weighted unless stated otherwise.

\section{[Place Figure 6 about here]}

Figure 6 plots the I-shock measure and the annual stock return difference between firms with low and high displaceable labor share, i.e. long-short portfolio with a long position in the bottom quintile of firms ranked by the AP measure and a short-position in the top quintile, the KML portfolio. These two time-series co-move very strongly and overlap in all spikes. The correlation coefficient is 0.60 . This strong co-movement is a robust feature of the data and it is present across various samples of firms. It holds when I exclude firms producing capital goods from the sample

and it is present independently among both, manufacturing and non-manufacturing firms. The co-movement is also not driven by firms' operating leverage or size (see figure IA.4 and table IA.22 in the online appendix for the long-short portfolio consisting of firms in these samples as well as portfolios controlling for operating leverage and size). This results indicates a very strong connection between macroeconomic variable measuring changes in capital goods prices and the dynamics of stock returns.

I first examine whether the co-movement of the KML portfolio with the I-shock measure is driven by ranking individual firms relative to industry peers or by ranking whole industries across the economy. Table III reports the correlation coefficients between the I-shock measure and the long-short portfolios based on the within- and between-industry variation in displaceable labor share, AP. The correlation is strong, 0.53-0.59, for long-short portfolios based on ranking whole industries. It is weak for long-short portfolios of firms ranked relative to industry peers. This is in agreement with the dominance of the between-industry variation in the AP measure discussed above (see panel $\mathrm{C}$ in table I). Both pieces of evidence underline the role of displaceable labor share as an industry characteristic.

[Place Table III about here] 
I next examine how the exposure to technology shocks varies across the five portfolios. Panel A of table IV reports the results from regressing annual portfolio returns on a constant and the Ishock measure. The first portfolio, consisting of stocks with the highest share of displaceable labor, has the strongest and most negative exposure to technology shocks. The estimated coefficients are negative for all five portfolios. They increase monotonically across all portfolios from -3.4 for the first portfolio to -1.0 for the fifth portfolio. The estimated coefficients are economically large and statistically significant for the first four portfolios. This result indicates that the strong comovement of the KML portfolio with the I-shock measure is generated by stocks with high share of displaceable labor. These stocks react negatively to technology shocks. The KML portfolio, i.e. Low-High AP, then exhibits positive and significant exposure to technology shocks of 2.3.

\section{[Place Table IV] about here]}

Panel B in table IV repeats the analysis controlling for the aggregate market return. The first portfolio has still the strongest and most negative exposure to technology shocks. The pattern of the estimated coefficients remains monotonic across the portfolios. A notable difference is that all coefficients of the I-shock measure are shifted up so that the fifth portfolio has a positive and significant exposure. The coefficients of the I-shock measure across the first three portfolios remain negative and statistically and economically significant. The KML portfolio has a positive and significant exposure to technology shocks of same magnitude, 2.4. The major part of this exposure, 1.6, comes again from the short position in the first portfolio consisting of firms with high share of displaceable labor.

Regressions in panel $\mathrm{C}$ control additionally for the size (SMB) and value (HML) factors as defined by Fama and French (1993). The results are very similar. The estimated coefficients of the I-shock measure increase monotonically across the portfolios from -1.4 for the first portfolio to 0.56 for the fifth portfolio. These results show that standard factors cannot explain the differential exposure to technology shocks across portfolios containing firms with low and high displaceable labor share. I show in online appendix table IA.14 that the results are also not driven by the profitability and investment factors of Fama and French (2015), the return difference between capital goods and consumption goods producers (IMC) of Papanikolaou (2011) and aggregate economic growth.

The findings in this section document that technology shocks embodied in capital have a strong and negative impact on firms with high share of displaceable labor. These firms are generally labor-intensive with relatively low capital but high use of labor that can be easily automated. Firms with low displaceable labor share usually have high capital or not easily replaceable labor and weak exposure to technology shocks. The results on firms' exposure presented in this section are consistent with the predictions of the theoretical model. 


\section{B. Firms' Exposure to Technology Shocks}

The previous section shows that the stock return differences between firms with low and high displaceable labor share, the KML portfolio, strongly correlate with the time-series of technology shocks, the I-shock measure. Hence, the KML portfolio is a reasonable, stock return-based measure capturing the time-series variation of technology shocks. I use the KML portfolio to estimate firms' exposure to technology shocks directly from the stock returns. Specifically, for each firm I estimate the exposure to technology shock, $\beta_{i}^{K M L}$, from a rolling regression:

$$
r_{i, t}=\alpha_{i}+\beta_{i}^{K M L} r_{K M L, t}+\epsilon_{i, t}
$$

where $r_{i, t}$ denotes firm $i^{\prime} s$ monthly excess return and $r_{K M L, t}$ is the monthly return on the KML portfolio. I estimate this regression for every stock in the sample each year at the end of June using monthly returns over the last 60 months ${ }^{32}$ This method allows the $\beta_{i}^{K M L}$ vary over time. The results reported below are robust to including market excess return and the size, and value factors of Fama and French (1993) as control variables in regression equation $26^{33}$

Technology shocks are a significant source of labor income and job displacement risk. The Ishock measure is a state variable indicating the labor income and job displacement risk, especially the risk of large adverse idiosyncratic events such as job loss that are pronounced in the higher moments of income growth distribution. The $\beta_{i}^{K M L}$ measures stock's exposure to the labor income risk directly from the covariances of the returns with the state variable. Hence, sorting stocks on the $\beta_{i}^{K M L}$ is conceptually different from sorting stocks on the share of displaceable labor, AP. Although these two variables are related and correlate strongly, $\beta_{i}^{K M L}$ captures stock $i^{\prime} s$ co-movement with a state variable that is highly relevant for investors marginal utility. The differences between sorting on characteristics and sorting on covariances has been discussed in number of previous studies, e.g. Daniel and Titman (1997).

I next examine the properties of the portfolios sorted by the $\beta^{K M L}$. Each year at the end of June, I sort stocks into five portfolios by their $\beta^{K M L}$ and hold the stocks in a given portfolio from July of year t to June of year $t+1$. Panel A of table $\mathrm{V}$ reports the post-ranking exposure to the I-shock measure across the portfolios. The exposure is estimated from regressing each portfolio's annual value-weighted return on a constant and the I-shock measure. The first portfolio consisting of stocks with low $\beta^{K M L}$ has strongly negative and significant exposure to the I-shock measure. The coefficients are then increasing, absolute values are decreasing, across the portfolios almost monotonically. The sole exception is the second portfolio, which has slightly more negative exposure to the I-shock than portfolio one. This result shows that $\beta^{K M L}$ successfully estimates firms' exposure to the underlying state variable, the I-shock measure. Firms' exposure to the KML portfolio predicts the exposure to the I-shock measure at horizon of at least one year. Panel B shows additional properties of stocks within each portfolio. The fifth portfolio contains stocks with

\footnotetext{
${ }^{32}$ I require the stock to have at least 30 observations in the last 60 months.

${ }^{33}$ The results are also robust when the KML portfolio is orthogonalized to the factors of Fama and French (1993).
} 
relatively low share of displaceable labor compared to stocks in portfolio one. This is consistent with low displaceable labor-share firms having weaker exposure to technology shocks ${ }^{34}$ The bookto-market ratio and market betas are slightly decreasing across the portfolios, while firm size is somewhat increasing. Other characteristics are flat across the portfolios or do not exhibit a clear pattern.

\section{[Place Table $\mathbf{V}$ about here]}

\section{Exposure to Technology Shocks and Return Premium}

In this section, I investigate whether a stock's expected return is related to the exposure of its returns to technology shocks, $\beta^{K M L}$. I estimate the stock return premium using the cross section of stocks. Then I examine the time variation and predictability of the premium. Finally, I show that stocks exposure implies differential employment and investment behavior consistent with the mechanism in the model.

\section{A. Return Premium}

To examine whether differences in stocks' exposure to technology shocks are associated with differences in their average returns, I sort stocks into five portfolios according to their $\beta^{K M L}$ as described in the previous section. For each portfolio, I calculate a time-series of monthly portfolio returns as value-weighted average returns (unless stated otherwise) across all stocks in the portfolio in a given month. The sample period is from 1975 to 201535

\section{[Place Table VI about here]}

Panel A of table VI reports the average annualized portfolio excess returns. The first portfolio has the highest average excess return, 12.45\%. This portfolio consists of stocks with the most negative $\beta^{K M L}$. The average excess returns decrease monotonically across the portfolios. The long-short, High-Low $\beta^{K M L}$, portfolio earns a negative premium of $-6.85 \%$ per year. This premium is statistically and economically significant.

The results are very similar for equally-weighted portfolio returns, reported in panel $\mathrm{B}$. The average excess returns decrease monotonically across the portfolios, although the return differences are smaller. This results in a somewhat smaller return premium of the High-Low $\beta^{K M L}$ portfolio, $-4.29 \%$ per year. The return premium is still statistically and economically significant.

I next examine whether the return differences can be explained by different exposures to aggregate market risk. Panel $\mathrm{C}$ reports the results of regressing the portfolio monthly returns on a constant and the market excess return. The estimated intercepts, alphas, exhibit similar pattern

\footnotetext{
${ }^{34}$ I show the time-series of the contemporaneous correlation between the share of displaceable labor AP and the $\beta^{K M L}$ at firm and industry level in appendix figure IA.5.

${ }^{35}$ The first five years 1970-1975 are used to estimate the $\beta^{K M L}$ for portfolios formed in June 1975.
} 
as average excess returns. The first portfolio has the highest alpha of $2.97 \%$ per year. The alphas decrease monotonically across portfolios. The High-Low $\beta^{K M L}$ earns a significant and negative alpha of $-5.39 \%$. Although the estimated coefficients of the market returns decrease somewhat across the portfolio, the differences in exposure to aggregate market risk cannot explain the differences in average returns.

Panel D reports estimates of regressions that include also the size (SMB) and value (HML) factors of Fama and French (1993) to control for potential exposure to these factors. The estimated alphas are slightly smaller in their magnitude when compared to panel $\mathrm{C}$, but the overall result is similar. The alphas decrease across the portfolios almost monotonically. The only exception is the second portfolio, whose alpha marginally exceeds the alpha of the first portfolio. The alpha of the High-Low $\beta^{K M L}$ portfolio is $-3.6 \%$ and is significant at the $10 \%$ level. Although the coefficients of the SMB factor also decrease across the portfolios, the differences in the exposure SMB factor do not explain the return premium. The pattern in the SMB coefficients is consistent with the evidence in table $\mathrm{V}$ indicating increasing stock size across the portfolios.

I repeat this analysis for the constituents of the S\&P500 index, which are the largest and most liquid stocks in the U.S. stock market. The results are very similar. They indicate a return premium for High-Low $\beta^{K M L}$ portfolio between $-7.16 \%$ and $-4.75 \%$ (see table IA.16 in the online appendix). Hence, the results do not depend on the presence of small and illiquid stocks 36

I next use panel regressions with firms' annual stock returns to differentiate the return premium for stocks' exposure to technology shocks, $\beta^{K M L}$, from well-known cross-sectional return predictors. Specifically, I run panel regressions at the firm level:

$$
R_{i, t+1}=\alpha+\gamma_{\beta_{i}^{K M L}} \times \beta_{i, t}^{K M L}+\sum_{n} \gamma_{n} \times X_{i, n, t-1}+\text { Year }_{t}+\epsilon_{i, t+1}
$$

where $R_{i, t+1}$ is firm $i^{\prime} s$ annual stock return from July of year $t$ to June of year $t+1, \beta_{i, t}^{K M L}$ is a firm's exposure to technology shock at the end of June of year $t, X_{i, n, t-1}$ are firm-level control variables at the end of year $t-1$, and $Y$ ear ${ }_{t}$ is year fixed effect 37

Table VII presents the results of estimating the panel regression 27. The specification in column (1) includes only a constant and $\beta^{K M L}$. The estimated coefficient is negative and strongly significant. The coefficient implies an average return differential of $-8.71 \%$ per year between firms with high and low $\beta^{K M L} 38$ Including the year fixed effect, column (2), leads to a lower coefficient that

\footnotetext{
${ }^{36}$ The results are also very similar when the stocks are sorted into portfolios based on $\beta^{K M L}$ that is estimated from multivariate rolling regressions including the size (SMB) and value (HML) factors of Fama and French (1993) as control variables (see table IA.17 in the appendix).

${ }^{37}$ The control variables $X_{i, n, t-1}$ that are based on data from firms' financial statements, i.e. book-to-market ratio, cashflow, financial leverage, price-to-cost margin, profitability, and size, are calculated from financial statements for fiscal year ending in year $t-1$. This allows a lag of 6-18 months for the information to become publicly available. Market beta $a_{t-1}$ is estimated over the last 60 months ending in June of year $t$. Turnover is calculated over the calendar year $t-1$.

${ }^{38} \mathrm{I}$ calculate the average return differential by multiplying the estimated coefficient of $\beta^{K M L}$, -3.829 , with the average difference in $\beta^{K M L}$ between the $95^{\text {th }}$ and $5^{\text {th }}$ percentile, 2.275. The average difference in $\beta^{K M L}$ is calculated as time-series average of contemporaneous differences in $\beta^{K M L}$ between the $95^{\text {th }}$ and $5^{\mathrm{P}}$ ercentile. The implied return premium for the average difference in $\beta^{K M L}$ between the $75^{\text {th }}$ and $25^{\text {th }}$ percentile is $-4.826 \%$.
} 
implies a return premium of $-3.64 \%$. Columns (3)-(10) show results for regressions that include $\beta^{K M L}$, year fixed effect and one of the control variables $X_{i, n, t}$. Each of these control variables has only a negligible impact on the estimated coefficient of $\beta^{K M L}$. The coefficients are negative and significant across the specifications with different control variables. The implied return difference between firms with high and low $\beta^{K M L}$ ranges from $-3.29 \%$ to $-4.62 \%$ per year. The regression in the last column controls jointly for all variables $X_{i, n, t}$ and the year fixed effect. The estimated coefficient of $\beta^{K M L}$ remains negative and statistically significant. The slightly higher magnitude implies an annual return premium of $-4.8 \%$.

\section{[Place Table VII about here]}

The estimated coefficients of $\beta^{K M L}$ imply a similar return premium for firms' exposure to technology shocks as the portfolio analysis described above. I show in online appendix table IA.18 that the estimation results are similar for the constituents of the S\&P500. The coefficient of $\beta^{K M L}$ is also robust to controlling for additional firm- and industry-level variables (see appendix tables IA.23 and IA.24.

The panel regressions assume a strictly linear relationship between stock returns and the crosssectional return predictors. To control for a potentially non-linear relationship, I use conditional double sorts. Specifically, in the first step I sort stocks into three baskets based on the value of the control variable. In the second step, I sorts the stocks within each of these baskets again into three additional baskets according to the $\beta^{K M L}$. This creates a total of 9 baskets. I then create three portfolios by pooling all stocks in the $\beta^{K M L}$-based baskets with the same rank. This procedure creates portfolios sorted on $\beta^{K M L}$ that are relatively independent of the return predictors used in the first step 39

Table VIII reports the average value-weighted portfolio returns. I first report the average portfolio returns for unconditional sorting on $\beta^{K M L}$, column (1). The average return differential based on unconditional sorting into three portfolios is $-6.6 \%$ per year. Column (2) shows results for $\beta^{K M L}$-sorted portfolios conditional on the book-to-market ratio. The portfolio with the low $\beta^{K M L}$ stocks has the highest average return of $10.83 \%$ per year. The average return decreases monotonically across the remaining two portfolios. The conditional High-Low $\beta^{K M L}$ portfolio earns a statistically and economically significant return premium of $-5.23 \%$ per year. This return premium is relatively independent of the differences in firms' book-to-market ratio. Columns (3)(9) show that conditioning the portfolio sorts on other cross-sectional return predictors provides very similar results. The average portfolio returns decrease across the portfolios. The premium for the High-Low $\beta^{K M L}$ portfolio ranges between $-4.21 \%$ and $-5.43 \%$ per year and is statistically significant and economically large. Results based on the constituents of S\&P500 are very similar (see appendix table IA.19). The return premium is also robust to conditioning on other firm- and industry-level variables (see appendix table IA.25 and IA.26). For a comparison, the last column

\footnotetext{
${ }^{39}$ In an alternative approach, I first calculate time-series of value-weighted portfolio returns for each of the nine conditionally-sorted portfolios. I then create three portfolios by calculating a simple average across the $\beta^{K M L}$-sorted portfolios with the same rank. The results based on this approach are very similar.
} 
shows the premium for the book-to-market ratio conditional on firms' size. The conditional value premium is $2.15 \%$ but not statistically significant.

The portfolio return analysis, panel regressions and conditional double sorts imply similar return premium for firms' exposure to technology shocks. The latter two methods show that the return premium is not driven by linear or non-linear relationship with well-known cross-sectional return predictors.

\section{[Place Table VIII about here]}

\section{B. Time Variation and Predictability of the Return Premium}

In this section, I examine whether the return premium varies over time and is predictable. As mentioned above, technology shocks are an important source of labor income and job displacement risk and the I-shock measure predicts higher moments of individual income growth distribution. Hence the I-shock measure can be considered a state variable for households' marginal utility. This evidence gives rise to the consideration that a return premium of an asset with a strong exposure to the technology shock is predictable by this state variable.

I use the I-shock measure to forecast the return premium of the Low-High $\beta^{K M L}$ portfolio. I focus on the Low-High $\beta^{K M L}$ instead of High-Low $\beta^{K M L}$ portfolio to facilitate the interpretation of the return premium. This portfolio has negative exposure to technology shocks and earns a positive return premium (see table VI). Specifically, I run forecasting regressions of the cumulative

$\log$ return premium for the Low-High $\beta^{K M L}$ portfolio, $\sum_{s=1}^{y} r_{t+s}^{\beta^{K M L}}$, over $y$ years, on the I-shock measure $I$ shock : $^{2}$

$$
\sum_{s=1}^{y} r_{t+s}^{\beta^{K M L}}=a^{(y)}+b^{(y)} \text { Ishock }_{t}+e_{t+y}^{(y)} .
$$

Panel A of table IX] reports the estimation results of the forecasting regression for the oneto five-year cumulative log return premium of the Low-High $\beta^{K M L}$ portfolio. The estimated coefficients have the expected positive sign; a decrease in relative prices of capital goods - positive technology shock increases the return premium. The estimated coefficients are marginally statistically significant for return horizons of two, three and four years. The magnitude of the coefficient is economically important. For example, a positive technology shock of one standard deviation increases the expected two-year return by $2.4 \%$. Panel B shows the results of the forecasting regressions that include additional forecasting variables. The estimated coefficient of the I-shock have similar magnitude and remain statistically significant for the same return horizons.

\section{[Place Table IX] about here]}

Figure 7 plots the I-shock measure and the subsequent realized three-years cumulative log return premium of the Low-High $\beta^{K M L}$ portfolio. The return premium varies over time together with the 
I-shock measure. Both time-series overlap relatively closely. Periods of substantial decreases in the relative prices of capital goods predict a high return premium for the Low-High $\beta^{K M L}$ portfolio.

\section{[Place Figure 7 about here]}

As discussed above, labor income and job displacement risk are high in states of large positive technology shocks. This evidence suggests that the time-varying return premium can be compensation for this type of risk. Households will seek a return premium for assets that have negative exposure to states of high labor income risk. The time variation of the return premium between the states of high and low technology shocks supports this explanation.

\section{Firms' Responses to Technological Shocks}

The evidence in earlier sections shows large differences in firms' risk exposure to technology shocks. In this section, I investigate whether firms with different exposure to technology shocks differ also in their employment, investment, sales and financial performance when the relative prices of capital goods decrease. Costly employment and capital adjustments, and changes in firms' sales following technology shocks can affect firms' financial performance and contribute to firms' risk exposure. To explore this mechanism, I estimate panel regressions in the form:

$$
\begin{aligned}
\Delta y_{i, t+s}= & b_{0} \text { Ishock }_{t}+b_{1} I_{i, t}^{\beta^{K M L}}+b_{2} \text { Ishock }_{t} \times I_{i, t}^{\beta^{K M L}} \\
& + \text { controls }_{i, t}+\operatorname{TFP}_{t}+\text { Trend }_{t}+e_{i, t+s}
\end{aligned}
$$

where $\Delta y_{i, t+s}$ is the firm $i^{\prime} s$ percentage change in employment, capital, capital-labor ratio, sales, percentage points change in return on capital, or return on equity between years $t$ and $t+3$, $I$ shock $k_{t}$ is the I-shock measure in year $t, I_{i, t}^{\beta^{K M L}}$ is an index between 0 and 9 indicating the decile of cross-sectionally ranked firms' exposure to technology shock, $\beta_{i, t}^{K M L}$, and $I s h o c k_{t} \times I_{i, t}^{\beta^{K M L}}$ is their interaction term. Controls $s_{i, t}$ is a set of firm-specific control variables consisting of firms' capital $K_{i, t}$, age $A g e_{i, t}$, market capitalization $S i z e_{i, t}$, firm fixed effects, and a lagged dependent variable at one-year horizon $t-1$ to $t$. The regressions include TFP shock $T F P_{t}$ and deterministic trend Trend $_{t}$ as aggregate control variables.

Panel A of table $\mathrm{X}$ reports the results of estimating regression equation (29) for changes in employment, capital and capital-labor ratio. The first column shows that a positive technology shock on average decreases firms' employment. The coefficient of the I-shock measure is negative, statistically significant and economically large. The effect of the technology shock differs significantly across firms with different $\beta_{i, t}^{K M L}$. The positive coefficient of the interaction term $I$ shock $k_{t} I_{i, t}^{\beta^{K M L}}$ indicates that the effect is stronger for firms with negative exposure to technology shocks. In the next two columns, I split the sample in halves based on firms $\beta^{K M L}$ and estimate the panel regression (29) without the interaction term. Firms in the first half have strongly negative exposure to technology shocks, while firms in the second half have only mild exposure that is much closer to 
zero (see table $\mathrm{V}$ ). The results show that firms with strongly negative exposure decrease employment following a positive technology shock. At the same time, employment is on average constant in firms with mild exposure over the same time horizon. The following three columns show that technology shocks increase firms' capital. The effect is approximately equal for firms with strongly negative and mild exposure. This result is consistent with evidence discussed above (see table II) and indicates that lower quality-adjusted relative prices of capital goods lead to higher investment. The last three columns show that technology shocks increase firms' capital-labor ratio. The effect is again stronger for firms with strongly negative exposure.

\section{[Place Table $\mathrm{X}$ about here]}

As described earlier, firms with strongly negative exposure to technology shocks are generally firms with very high share of displaceable labor (see table V]. The results indicate that these firms indeed adjust, potentially automate, their production processes by decreasing the number of employees and investing in capital when a technology shock occurs.

Panel B reports the results of the percentage changes in sales and percentage point changes in return on capital and return on equity. The first column shows that a technology shock has negative impact on firms' sales. The estimated coefficient is statistically and economically significant. The following two columns show that the effect is stronger for firms with strongly negative exposure. The estimated coefficient of the I-shock measure is more than twice as large for firms with strong exposure compared to firms with mild exposure. The next three columns show that lower relative prices of capital goods decrease firms' return on capital. This effect is again larger for firms with strong risk exposure. The estimates in the last three columns indicate also negative and strongly differential effect of technology shock on the return on equity. Firms with strongly negative exposure experience decreases in return on equity almost twice as large as firms with mild exposure. The estimated coefficients are statistically significant and economically large.

I repeat the analysis for different time horizons. I report the results for a time horizon of three years in appendix table IA.27. The results are qualitatively very similar. The estimated coefficients are generally larger as they refer to changes compounded over three years. These results indicate that the differential effects of technology shocks between firms with strong and mild risk exposure are not driven by potential lead-lag differences in firms' responses.

The theoretical model presented earlier highlights the importance of competition for the economic mechanism how technology shocks affect firm value through costly technology adoption. Hence, one can easily develop an intuition that the effects of technology shocks will be larger in highly competitive industries. I next investigate whether the effects of the technology shocks differ between firms in highly competitive and less competitive industries. To test this conjecture, I split the sample into two halves by the degree of competition and estimate the panel regression (29) without the interaction term for firms with strong and mild exposure within each half separately. I measure the degree of industry competition by the Herfindahl-Hirschman index of sales at the level of SIC 3 digit industries. 
Panel A of table XI reports the results for percentage changes in employment and capital. The estimated coefficients have the same sign as discussed earlier. A positive technology shock decreases firms' employment and increases capital. For firms with strongly negative exposure, these effects are stronger in highly competitive industries. For firms with mild exposure, the effect on capital is stronger in highly competitive industries, but the effect on employment is weaker.

\section{[Place Table XI about here]}

Panel B reports the results for percentage changes in capital-labor ratio and sales. The estimated coefficients of the I-shock measure have uniformly higher magnitude in highly competitive industries for both firms with strong and mild exposure. Firms with strongly negative exposure increase their capital-labor ratio upon the occurrence of a technology shock more if they are in highly competitive industries. These firms experience also more severe decrease in sales in comparison to firms in less competitive industries. This pattern holds equally for firms with mild exposure.

In panel C, I report the results for percentage point changes in return on capital and return on equity. The effects of the technology shocks on these two variables are generally more pronounced in highly competitive industries. Firms experience a stronger decrease in the return on capital as well as in the return on equity if they are in more competitive industries.

The findings in this section document that firms with differential exposure to technology shocks have different employment and capital adjustment in years following a decrease in prices of capital goods, while financial performance is also affected. Firms with strongly negative exposure have generally high share of displaceable labor and tend to increase their capital-labor ratio after technology shocks. During this process they experience lower sales, return on capital and return on equity. This evidence indicates that the risk exposure to technology shocks reflects firms' financial underperformance after the shocks. Industry competition generally increases the observed effects.

\section{Conclusion}

The potential of capital to substitute some types of labor and complement others plays a central role in economic models that study the effects of technological change. I find that firms' potential to automate the production process is also an important determinant of firms' exposure to technology shocks. Technology shocks embodied in capital are an important driver of stock returns with a differential impact over the cross section of stocks.

I show theoretically that the firms' share of displaceable labor that can be automated by capital can increase firms' riskiness in a competitive environment. Firms in industries with high displaceable labor share have negative exposure to technology shocks that facilitate automation. Automation becomes a costly necessity for firms to stay competitive as competition eliminates its benefits for firms and passes them to the consumers in form of lower product prices. This result is strongly supported by empirical evidence. 
I show empirically that firms with high share of displaceable labor have very strong and negative exposure to technology shocks. I document that a macroeconomic measure of technology shocks based on prices of capital goods can be successfully approximated by stock returns of a zero-cost portfolio based on firms' share of displaceable labor and this portfolios has captured all major technology shocks over the last four decades. I further show that firms exposure to technology shocks that facilitate automation earn a robust and time-varying return premium that can be empirically and theoretically rationalized as a compensation for households' job displacement and labor income risk. The exposure to technology shocks is associated with firms' adjustment of the capital-labor ratio and underperformance after a decrease in relative prices of capital goods consistent with the model prediction.

My model abstracts from other interesting economic aspects such as market entry, differential ability to adopt new technology or operating leverage, which are certainly relevant in some real world scenarios and worth exploring both empirically and theoretically. Future research can also focus on a multiperiod fully dynamic setting of my model with endogenous arrival of technology shocks. Such model can deliver richer implications for asset prices as well as implications for differential growth between heterogeneous industries. 


\section{Appendix A. Equilibrium and Market Clearing Conditions}

The CES aggregator technology at the sector implies optimal demand functions for the firmspecific goods of the form:

$$
Y_{f, s, t}=\left(\frac{P_{f, s, t}^{l}}{P_{s, t}}\right)^{-\nu} Y_{s, t} \quad \text { and } \quad Y_{f, s, t}=\left(\frac{P_{f, s, t}^{k}}{P_{s, t}}\right)^{-\nu} Y_{s, t} \quad \text { for } \quad s=1,2 \text { and } t=1,2
$$

The CES aggregator technology at the aggregate level implies optimal demand function for the sector-specific goods of the form:

$$
Y_{s, t}=\left(\frac{P_{s, t}}{P_{A, t}}\right)^{-\rho} Y_{A, t}
$$

Market clearing condition for the aggregate good is defined as

$$
\sum_{h=1}^{N_{h}} c_{h, t}=Y_{A, t}
$$

Market clearing on the labor markets is defined as:

$$
\begin{gathered}
L_{1,1}^{l}=\sum_{h=1}^{N_{h}} L_{h, 1,1} \\
L_{1,2}^{l}+L_{1,2}^{k}=\sum_{h=1}^{N_{h}} L_{h, 1,2} \\
L_{1, t}^{k}=\sum_{h=1}^{N_{h}} L_{h, 2, t} \quad \text { for } \quad t=1,2
\end{gathered}
$$

where the $L_{s, t}^{l}$ is labor used directly in goods production in sector $s$ and $L_{s, t}^{k}$ is labor used in production of capital in sector $s$. The market clearing on the investment capital market is:

$$
\begin{gathered}
\sum_{f=1}^{N} K_{f, 1,2} \mathbb{1}\{\text { Automated }=\text { Yes }\}_{f, 1,2}=K_{1, t}^{\alpha} \\
\sum_{f=1}^{N} K_{f, 2, t}=K_{2, t}^{\alpha} \quad \text { for } \quad t=1,2 .
\end{gathered}
$$

\section{Appendix B. The O*NET Database}

The $\mathrm{O}^{*}$ NET database provides a comprehensive set of characteristics describing occupations in a number of dimensions such as workers' abilities, skills, knowledge and experience, work values, work styles, work activities, etc. The $\mathrm{O}^{*} \mathrm{NET}$ collects the underlying data in a two-stage design. First, O*NET selects a statistically random sample of businesses that are expected to employ targeted occupations. Second, it selects a random sample of workers in the targeted occupations 
within those businesses and collects the data by surveying the job incumbents using questionnaires. Additional variables such as variables describing skills and abilities are developed from the workers' responses by occupational analysts. O*NET continuously updates the occupational characteristics by ongoing surveys and provides updated occupational characteristics in new database releases quarterly/semi-annually starting from 2003. This procedure allows to track the changes in occupational characteristics. The first releases of the O*NET database before 2003, however, are based on the data from Dictionary of Occupational Titles (DOT), which is a predecessor of $\mathrm{O}^{*} \mathrm{NET}$. The underlying data in DOT refers to years 1991 (revised 4th edition) and 1977 (4th edition). The number of occupations in the $\mathrm{O}^{*} \mathrm{NET}$ database releases varies between 812 and 1122 occupations depending on the occupational classification used in each database release. The occupations are currently classified by the 2010 O*NET - Standard Occupational Classification (O*NET SOC) that is a refined classification based on 2010 Standard Occupational Classification (SOC). 40

\section{Appendix C. Validity and Robustness of the RTI Measure}

The construction of the RTI measure involves some degree of subjectivity in selecting the underlying descriptors as well as in the aggregation of the task inputs into one number expressing the routine task intensity. To address the potential concerns stemming from the freedom of selecting the underlying descriptors, I constructed alternative RTI measures from subsets and extended sets of descriptors and found that alternative measures identify routine and non-routine occupations in a very similar way. An aggregation of the underlying task inputs without logarithmic transformation as in formula 24 also generates very comparable RTI measure. I also compare my RTI measure with the original RTI measure from Autor and Dorn (2013). When matched to the common occupational classification, the measures have strong positive correlations across the occupations. Routine intensive occupations identified by each of these measures overlap and the overlap is also strong for non-routine occupations. The fact that these measures are constructed from different data sources and using different occupational characteristics but still succeed to identify the occupational routine task intensity in a very similar way increases the validity of these measures. Despite these validity and robustness checks, the use of the RTI measure still requires caution. First the underlying data can still be subject to some measurement errors and the selected descriptors may not necessarily describe all dimensions of routine intensity or automation potential of a given occupation. Second the RTI measure is defined only up to the occupational level and hence omits any variation in the routine task intensity across workers in the same occupation or of the same occupation across different firms. Given these concerns, the RTI measure has to be considered as an imprecise measure of the routine tasks and automation potential ${ }^{41}$ Second, the given specification of the RTI measure is still time- and technology-dependent. Although, I use multiple data sources that update the occu-

\footnotetext{
${ }^{40}$ The previous releases of the $\mathrm{O}^{*} \mathrm{NET}$ database are based on previous versions of O*NET-SOC, namely 2000, 2006, and 2009. The first release of the O*NET database in 1998 uses O*NET 98 OU classification that is based on the Occupational Employment Statistics classification (OES classification).

${ }^{41}$ David (2013) discusses the challenges of measuring task inputs in more detail.
} 
pational characteristics over time, the choice of the underlying descriptors reflects the current and past state of the technology. For instance, 'Operating vehicles, mechanized devices, or equipment' is used as a descriptor of non-routine manual task input. Using this measure, occupations such as bus, truck, and taxi drivers or commercial pilots are ranked as non-routine which reflects the state of the technology in most of the 20th century. The advances in technology, however, change the character of these occupations towards more routine intensive and potentially automatable. For example, various version of autopilots are widely used in commercial airplanes and their capabilities to assist during different phases of the flight have been constantly increasing. Similarly, a number of tasks involved in driving a car or truck, such as manually changing the gears or navigation, have been automated or significantly facilitated. Currently a number of companies both within and outside of car manufacturing are developing and testing systems for autonomous/automated vehicles. Given the ongoing changes in the available technology, this descriptor, 'Operating vehicles, mechanized devices, or equipment', may be re-classified to measure routine manual input in near future.

I match the RTI measured at the occupational level to firm-level observations by the OES conducted by Bureau of Labor Statistics. OES provides detailed tables of occupational composition of the labor force at a detailed industry level starting from 1988. The industries are classified at SIC 3-digit or NAICS 4-digit level across the whole U.S. economy. The number of industries ranges between 290 and 378 42 I extrapolate the occupational composition from the first OES releases to the years before 1988 to extend my sample to 1970. To translate the RTI measure from occupational level to industry level, I calculate for each industry the percentage of employees employed in routine intensive occupations. I define routine intensive occupations as occupations above the top employment-weighted tercile of occupations ranked by RTI score in a given year ${ }^{43}$ I report the exact match of the underlying OES file and the corresponding release of the O*NET database in the online appendix table IA.21. I transform the RTI from industry to firm level by imposing the percentage of employees in routine occupations in a given industry to all firms in that industry. Since the main focus of this paper is on the between-industry variation, the omission of the intra-industry variation in the RTI is not a limitation. Moreover, I will show in the subsequent text that there is a strong relationship between labor-intensity and routine task intensity.

To validate the AP measure, I examine whether it can predict future automation. Automation, generally, refers to the substitution of machines or equipment for human workers in performing specific tasks. This can be reflected in various adjustments such as higher use of machines, reduction of employment and/or changes in the use of technology by specific occupations. Table IA.8 in online appendix shows that industry's share of routine labor predicts the use of information and communication equipment (ICT) per worker over the following two decades. This relationship is especially strong for manufacturing industries and is robust to other factors such as offshorability and import penetration. I next examine whether the RTI also predicts the use of technology within

\footnotetext{
${ }^{42}$ I report the exact number of industries in each OES release in online appendix, table IA.20

${ }^{43}$ The results in the subsequent sections are very similar if I use different thresholds such as 70 -th percentile or 80-th percentile.
} 
occupations. For each occupation, I calculate a technology-use index measuring the use of various forms of technology such as computers and electronics and the importance of technology-relevant skills such as programming or controlling machines. I report the full set of the underlying variables in online appendix table IA.6. Table IA.9 in online appendix shows that occupational routine task intensity predicts the use of technology at occupational level. Occupations with relatively higher RTI score experienced relatively higher increase in the technology-use index in the following years. These two results indicate that the AP measure and its component, the RTI measure, indeed predict automation at industry and occupational level, respectively. ${ }_{4}^{44}$

\section{Appendix D. Filtering the Stock Return Data}

The sample consists of common stocks listed at the NYSE, NASDAQ, and AMEX. I exclude financials SIC 6000-6799, utilities SIC 4900-4999, and public sector companies SIC $\geq 9000$. To avoid the results to be driven by small and micro-cap firms, I exclude the bottom $20 \%$ of firms ranked by market capitalization. I also exclude the bottom $10 \%$ of firms ranked by the share price. The results are similar when firms with share price below 2 dollars are excluded. I further exclude firms in the bottom $5 \%$ by trading volume. Results are similar when more restrictive percentiles are applied. I further exclude firms with less than 500 employees or total net property, plant and equipment less than 5 millions. Estimation of firm's betas requires the firm to have monthly data over at least last 30 months. The sample of S\&P500 firms consists of the continuously updated index constituents constituents. I also exclude financials and utilities.

\section{Appendix E. Measuring the Technology Shocks Embodied in Capital, Details}

I formally derive the validity of the I-shock measure in a simple two-sector model from Cummins and Violante (2002). Final goods producers competitively produce final goods $x_{t}$ at price $p_{t}^{c}$. The final goods can be either consumed or used as an input for production of capital goods. The capital goods sector can produce $i_{t}$ efficiency units from $x_{t}$ units of consumption goods according to production function $i_{t}=q_{t} x_{t} . q_{t}$ captures the level of technology in the capital goods sector. Prices in the capital goods sector are set competitively so that $p_{t}^{i} i_{t}=p_{t}^{c} x_{t}$. Combining this result with the production function leads to $p_{t}^{i} / p_{t}^{c}=1 / q_{t}$ and hence $\Delta q_{t}=\Delta p_{t}^{c}-\Delta p_{t}^{i}$. Accordingly, the changes in the prices of capital goods relative to consumption goods measure the investment specific technology shock $q_{t}$. Based on this model, I construct the measures of the technology shock by subtracting the annual log changes in the quality-adjusted prices of capital goods from the log

\footnotetext{
${ }^{44}$ Other studies also provide supportive evidence. For instance, a companion paper Knesl (2018) shows that manufacturing industries with high share of routine labor substitute equipment capital for human workers following technology shocks. Autor and Dorn (2013) document a differential reduction of employment of routine occupations in commuting zone with originally high share of routine labor. Spitz-Oener (2006) documents a differential increase in requirements for complex skills in rapidly computerizing occupations.
} 
changes in prices of consumption goods. Accordingly, an increase in the I-shock measure indicates a positive technology shock embodied in capital.

The prices of the capital goods are from the price index of private fixed investment in nonresidential equipment provided by the U.S. Bureau of Economic Analysis. This price index is a composite of price indexes of 25 different types of equipment that are broadly categorized as information processing equipment, industrial equipment, transportation equipment, and other equipment. I measure the aggregate prices by the BEA's price index of personal consumption expenditures for nondurable goods. The sampling frequency of both time series is annual. I use the data from 1970 to 2015. To account for possible bias due to lack of quality adjustment in the price indexes of capital goods, I use the underlying data from Cummins and Violante (2002) and extrapolate the quality adjustment until 2015. The data in Cummins and Violante (2002) directly accounts for the quality changes in the 24 types of equipment that comprise the aggregate price index of capital goods. The quality adjustment is based on the original data from Gordon (1990). To construct the I-shock measure, I subtract the log change in the quality-adjusted prices of capital goods from the log change in prices of nondurable consumption goods. I also calculate an alternative measure without using the quality adjustment from Cummins and Violante (2002). This measure relies completely on the quality adjustment in the underlying price indexes from BEA. The results in this paper are very similar when I use the alternative measure. The time-series variation of both measures is very similar. The major difference between the quality-adjusted and the alternative measure is the long-term average. The average is higher for the quality-adjusted measure as it reflects the improvements in quality of the capital goods over time. 


\section{REFERENCES}

Abis, Simona, 2017, Man vs. machine: Quantitative and discretionary equity management, Unpublished working paper. Columbia Business School .

Acemoglu, Daron, and David Autor, 2011, Skills, tasks and technologies: Implications for employment and earnings, Handbook of labor economics 4, 1043-1171.

Acemoglu, Daron, and Pascual Restrepo, 2017, Robots and jobs: Evidence from us labor markets .

Acemoglu, Daron, and Pascual Restrepo, 2018, The race between man and machine: Implications of technology for growth, factor shares, and employment, American Economic Review 108, 14881542.

Atkeson, Andrew, and Patrick J Kehoe, 2007, Modeling the transition to a new economy: lessons from two technological revolutions, American Economic Review 97, 64-88.

Autor, David, and David Dorn, 2013, The growth of low-skill service jobs and the polarization of the us labor market, The American Economic Review 103, 1553-1597.

Autor, David H, Frank Levy, and Richard J Murnane, 2003, The skill content of recent technological change: An empirical exploration, The Quarterly journal of economics 118, 1279-1333.

Bartlesman, Eric, and Wayne B Gray, 1996, The nber manufacturing productivity database.

Becker, Randy, Wayne Gray, and Jordan Marvakov, 2013, Nber-ces manufacturing industry database: Technical notes, NBER Working Paper 5809.

Belo, Frederico, Jun Li, Xiaoji Lin, and Xiaofei Zhao, 2017, Labor-force heterogeneity and asset prices: The importance of skilled labor, The Review of Financial Studies 30, 3669-3709.

Belo, Frederico, Xiaoji Lin, and Santiago Bazdresch, 2014, Labor hiring, investment, and stock return predictability in the cross section, Journal of Political Economy 122, 129-177.

Bretscher, Lorenzo, 2017, From local to global: Offshoring and asset prices .

Brynjolfsson, Erik, and Andrew McAfee, 2014, The second machine age: Work, progress, and prosperity in a time of brilliant technologies (WW Norton \& Company). 
Bustamante, M Cecilia, and Andres Donangelo, 2017, Product market competition and industry returns, The Review of Financial Studies 30, 4216-4266.

Campbell, John Y, and Robert J Shiller, 1988, Stock prices, earnings, and expected dividends, The Journal of Finance 43, 661-676.

Chen, Huafeng Jason, Marcin Kacperczyk, and Hernan Ortiz-Molina, 2011, Labor unions, operating flexibility, and the cost of equity, Journal of Financial and Quantitative Analysis 46, 25-58.

Constantinides, George M, and Darrell Duffie, 1996, Asset pricing with heterogeneous consumers, Journal of Political economy 104, 219-240.

Constantinides, George M, and Anisha Ghosh, 2017, Asset pricing with countercyclical household consumption risk, The Journal of Finance 72, 415-460.

Corhay, Alexandre, 2017, Industry competition, credit spreads, and levered equity returns .

Corhay, Alexandre, Howard Kung, and Lukas Schmid, 2017, Competition, markups and predictable returns .

Cummins, Jason G, and Giovanni L Violante, 2002, Investment-specific technical change in the united states (1947-2000): Measurement and macroeconomic consequences, Review of Economic dynamics 5, 243-284.

Daniel, Kent, and Sheridan Titman, 1997, Evidence on the characteristics of cross sectional variation in stock returns, the Journal of Finance 52, 1-33.

David, H, 2013, The" task approach" to labor markets: an overview, Technical report, National Bureau of Economic Research.

Donangelo, Andres, 2014, Labor mobility: Implications for asset pricing, The Journal of Finance 69, 1321-1346.

Eisfeldt, Andrea L, and Dimitris Papanikolaou, 2013, Organization capital and the cross-section of expected returns, The Journal of Finance 68, 1365-1406.

Fama, EF, and KR French, 2015, A five-factor asset pricing model.[fama-miller working paper]. 2014, Journal of Financial Economics 116, 1-22. 
Fama, Eugene F, and Kenneth R French, 1993, Common risk factors in the returns on stocks and bonds, Journal of financial economics 33, 3-56.

Favilukis, Jack, and Xiaoji Lin, 2015, Wage rigidity: A quantitative solution to several asset pricing puzzles, The Review of Financial Studies 29, 148-192.

Favilukis, Jack, and Xiaoji Lin, 2016, Does wage rigidity make firms riskier? evidence from longhorizon return predictability, Journal of Monetary Economics 78, 80-95.

Fisher, Jonas DM, 2006, The dynamic effects of neutral and investment-specific technology shocks, Journal of political Economy 114, 413-451.

Fox, Douglas R, and Clinton P McCully, 2016, Concepts and methods of the u.s. national income and product accounts.

Garlappi, Lorenzo, and Zhongzhi Song, 2016, Can investment shocks explain the cross section of equity returns?, Management Science 63, 3829-3848.

Garlappi, Lorenzo, and Zhongzhi Song, 2017, Capital utilization, market power, and the pricing of investment shocks, Journal of Financial Economics 126, 447-470.

Gârleanu, Nicolae, Leonid Kogan, and Stavros Panageas, 2012, Displacement risk and asset returns, Journal of Financial Economics 105, 491-510.

Gârleanu, Nicolae, and Stavros Panageas, 2017, Finance in a time of disruptive growth .

Gordon, Robert J, 1990, The measurement of durable goods prices (University of Chicago Press).

Greenwood, Jeremy, Zvi Hercowitz, and Gregory W Huffman, 1988, Investment, capacity utilization, and the real business cycle, The American Economic Review 402-417.

Greenwood, Jeremy, Zvi Hercowitz, and Per Krusell, 1997, Long-run implications of investmentspecific technological change, The American Economic Review 342-362.

Greenwood, Jeremy, Zvi Hercowitz, and Per Krusell, 2000, The role of investment-specific technological change in the business cycle, European Economic Review 44, 91-115.

Greenwood, Jeremy, and Boyan Jovanovic, 1999, The information-technology revolution and the stock market, American Economic Review 89, 116-122. 
Greenwood, Jeremy, and Mehmet Yorukoglu, 1997, 1974, in Carnegie-Rochester conference series on public policy, volume 46, 49-95, Elsevier.

Griliches, Zvi, 1961, Hedonic price indexes for automobiles: An econometric of quality change, in The Price Statistics of the Federal Goverment, 173-196 (NBER).

Guvenen, Fatih, Serdar Ozkan, and Jae Song, 2014, The nature of countercyclical income risk, Journal of Political Economy 122, 621-660.

Hansen, Lars Peter, and Robert J Hodrick, 1980, Forward exchange rates as optimal predictors of future spot rates: An econometric analysis, Journal of Political Economy 88, 829-853.

Hobijn, Bart, and Boyan Jovanovic, 2001, The information-technology revolution and the stock market: Evidence, American Economic Review 91, 1203-1220.

Hornstein, Andreas, and Per Krusell, 1996, Can technology improvements cause productivity slowdowns?, NBER Macroeconomics annual 11, 209-259.

Hou, Kewei, and David T Robinson, 2006, Industry concentration and average stock returns, The Journal of Finance 61, 1927-1956.

Hou, Kewei, Chen Xue, and Lu Zhang, 2017, Replicating anomalies, Technical report, National Bureau of Economic Research.

Jovanovic, Boyan, and Peter L Rousseau, 2005, General purpose technologies, in Handbook of economic growth, volume 1, 1181-1224 (Elsevier).

Knesl, Jiří, 2018, Job displacement through technology, how technological shocks affect households' income and unemployment .

Kogan, Leonid, and Dimitris Papanikolaou, 2013, Firm characteristics and stock returns: The role of investment-specific shocks, The Review of Financial Studies 26, 2718-2759.

Kogan, Leonid, and Dimitris Papanikolaou, 2014, Growth opportunities, technology shocks, and asset prices, The journal of finance 69, 675-718.

Kogan, Leonid, Dimitris Papanikolaou, and Noah Stoffman, 2017, Winners and losers: Creative destruction and the stock market, Technical report, National Bureau of Economic Research. 
Krusell, Per, Lee E Ohanian, José-Víctor Ríos-Rull, and Giovanni L Violante, 2000, Capital-skill complementarity and inequality: A macroeconomic analysis, Econometrica 68, 1029-1053.

Kuehn, Lars-Alexander, Mikhail Simutin, and Jessie Jiaxu Wang, 2017, A labor capital asset pricing model, The Journal of Finance 72, 2131-2178.

Lettau, Martin, and Sydney Ludvigson, 2001, Consumption, aggregate wealth, and expected stock returns, the Journal of Finance 56, 815-849.

Loualiche, Erik, et al., 2014, Asset pricing with entry and imperfect competition, Unpublished manuscript, Sloan School of Management, MIT .

Newey, Whitney K, and Kenneth D West, 1987, A simple, positive semi-definite, heteroskedasticity and autocorrelation consistent covariance matrix, Econometrica (1986-1998) 55, 703.

Papanikolaou, Dimitris, 2011, Investment shocks and asset prices, Journal of Political Economy 119, 639-685.

Pástor, L'uboš, and Pietro Veronesi, 2009, Technological revolutions and stock prices, American Economic Review 99, 1451-83.

Schmidt, Lawrence, 2016, Climbing and falling off the ladder: Asset pricing implications of labor market event risk .

Spitz-Oener, Alexandra, 2006, Technical change, job tasks, and rising educational demands: Looking outside the wage structure, Journal of labor economics 24, 235-270.

Wasshausen, David, Brent R Moulton, et al., 2006, The role of hedonic methods in measuring real gdp in the united states, Technical report, Bureau of Economic Analysis.

Zeira, Joseph, 1998, Workers, machines, and economic growth, The Quarterly Journal of Economics 113, 1091-1117.

Zhang, Miao Ben, 2018, Labor-technology substitution: Implications for asset pricing, Journal of Finance, forthcoming . 


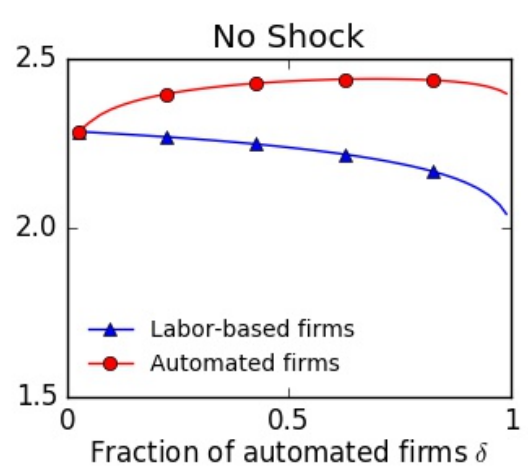

Panel A. Prices of Firm Goods
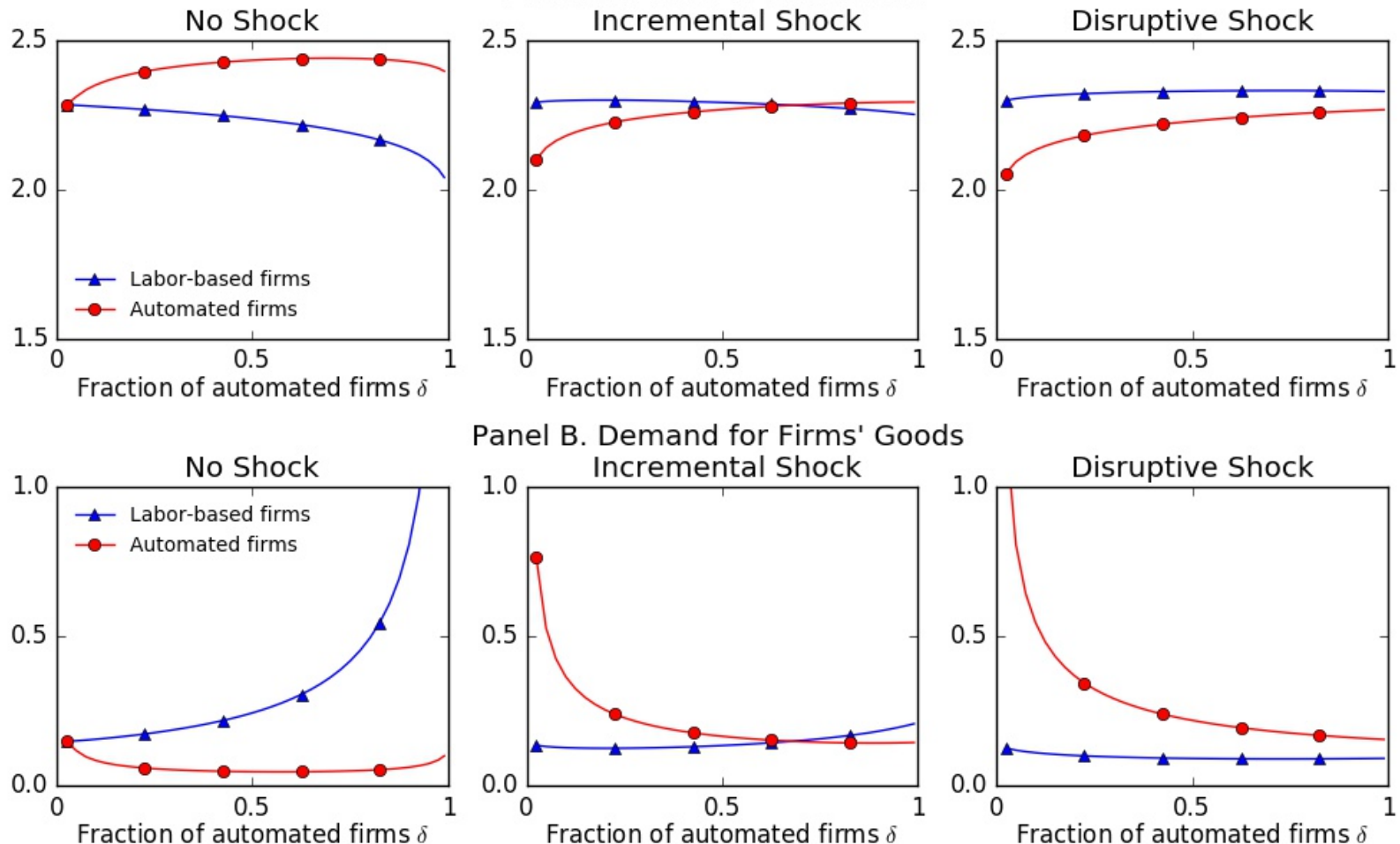

Panel B. Demand for Firms' Goods
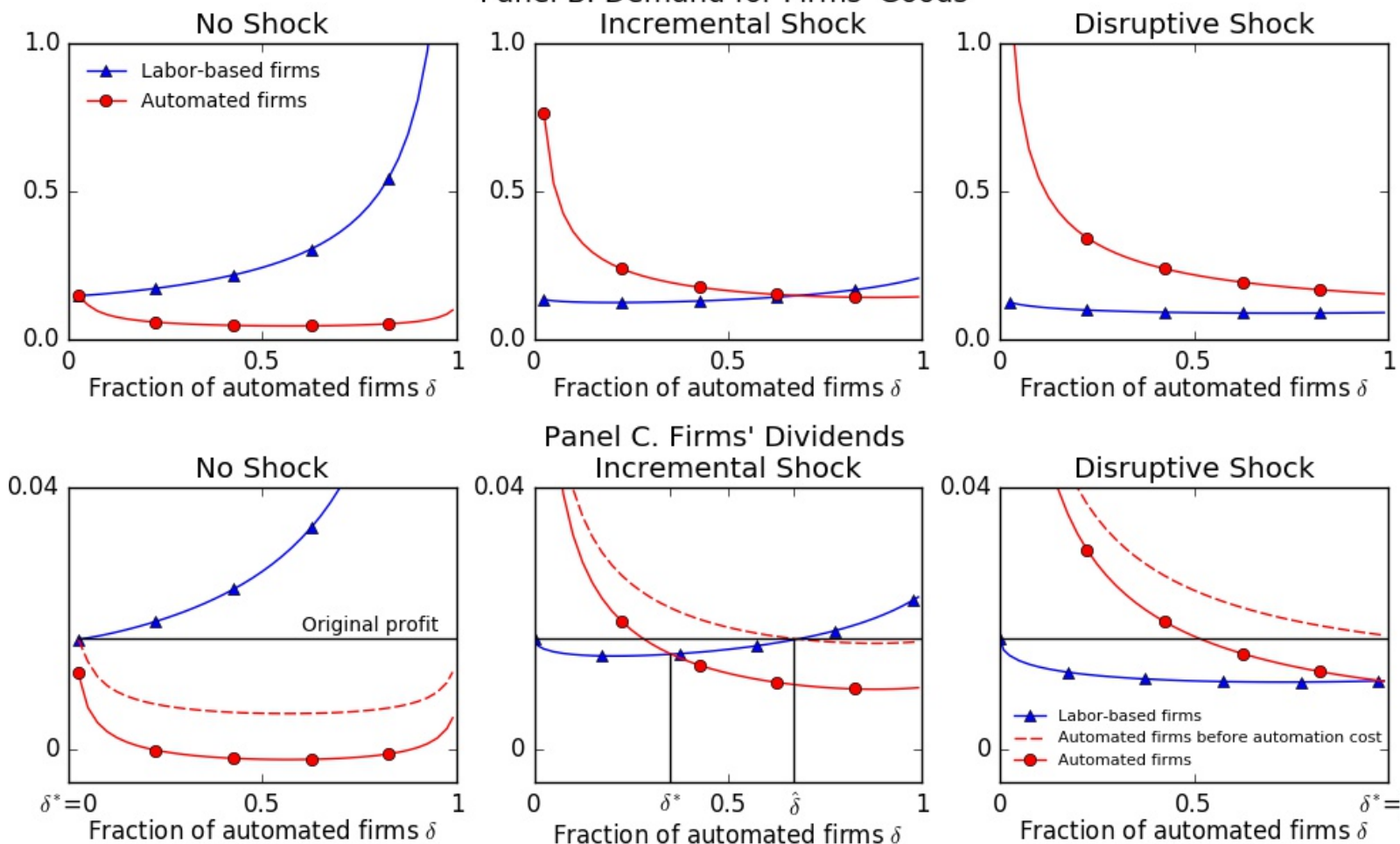

Panel C. Firms' Dividends
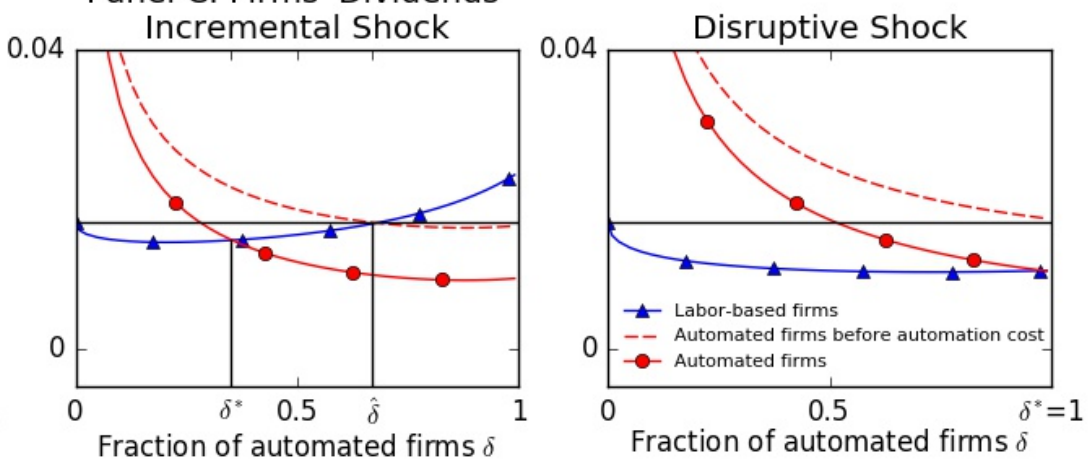

Figure 2. Three Types of Sector Equilibria. This figure plots the relationship between the prices of goods (panel A), demand for goods (panel B), and dividends (panel C) of labor-based and automated firms and the percentage of automated firms $\delta$ within the sector. Plots in the first column show a state of no shock. The parameter $z_{2}$ is chosen so that the good prices of each type of firm are same when no firm automates $\left(\delta^{*}=0\right)$. Plots in the middle column show a situation with an incremental technology shock when a percentage of firms $\left(0<\delta^{*}<1\right)$ automates. Plots on the right-hand side show a situation of large disruptive technology shocks when all firms in the sector automate despite automation $\operatorname{cost} \kappa,\left(\delta^{*}=1\right)$. The black horizontal line depicts the original dividend level. The model parameters are: $\rho=0.6, \nu=0.95, \chi=1, \theta=2, N=1000, N_{h}=100$, $A^{\text {Low }}=0.85, A^{\text {High }}=0.95,1.05, \beta=0.85, \gamma=21, \epsilon=0.39, p_{H}=0.15, p_{\epsilon}=0.5$, and $\kappa=8 \times 10^{-5}$. Demand fo firms' goods and firms' dividends are scaled by a factor 100 . 

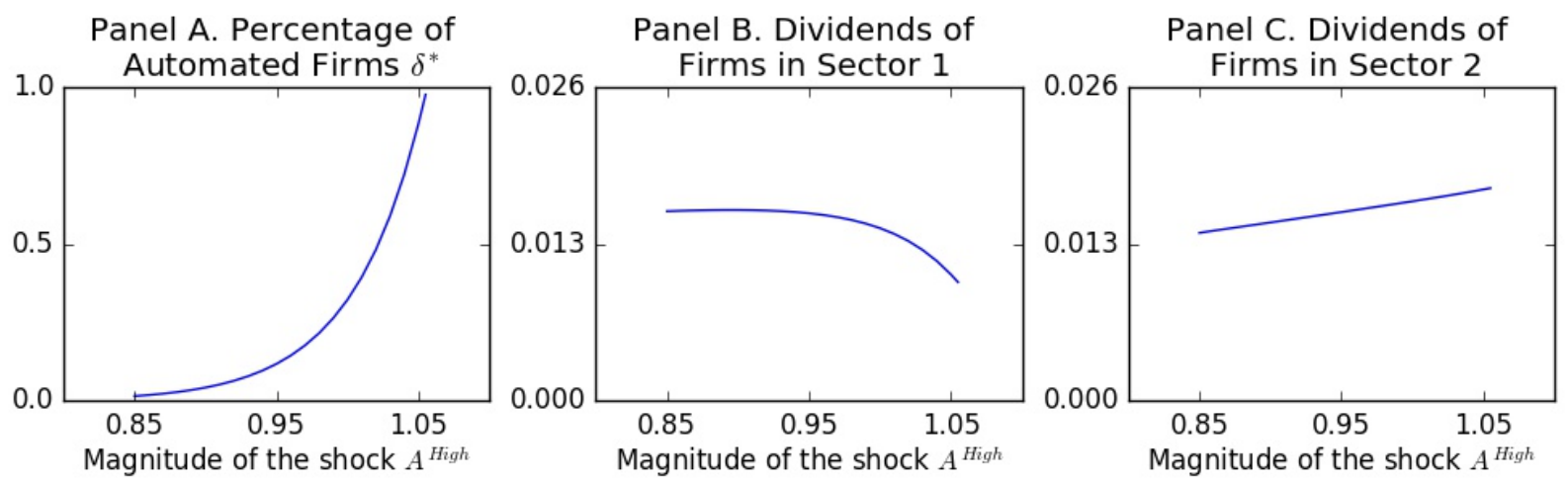

Figure 3. Technological Shocks, Equilibrium Automation, and Profits. This figure plots the equilibrium relationship between the magnitude of the technology shock $A_{t}$ and percentage of firms that automate within the sector 1 (panel A), the dividends of firms in sector 1 (panel B) and the dividends of firms in sector 2 (panel C). Model parameters are stated in the description of figure 2. Dividends are scaled by a factor 100 .
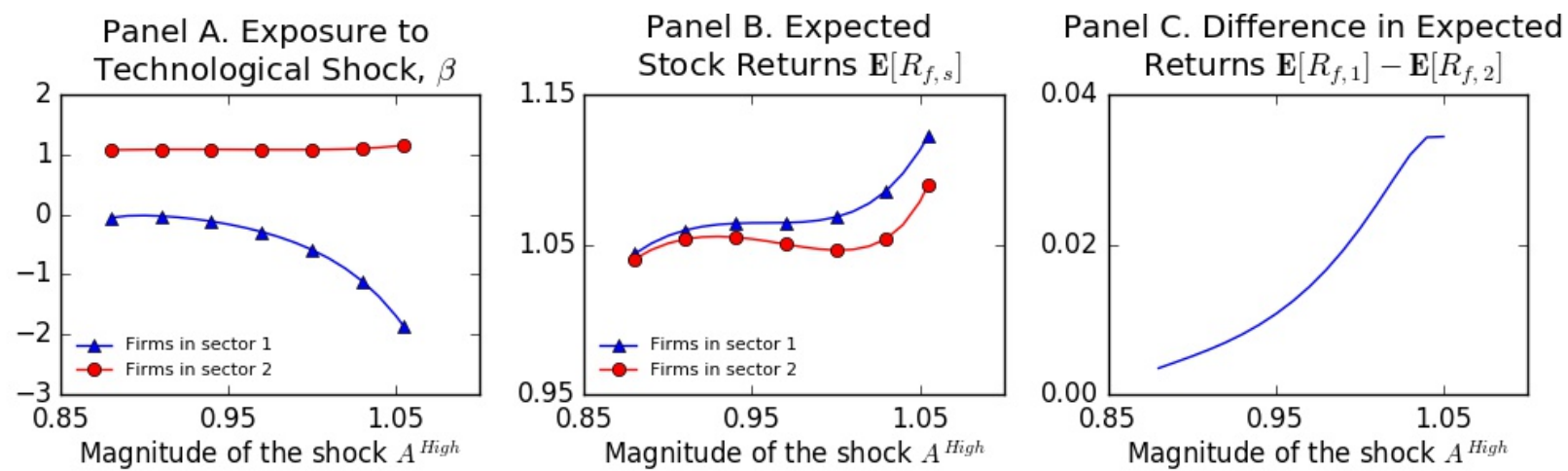

Figure 4. Firms' Exposure to Technological Shock and Expected Returns. This figure plots the relationship between the magnitude of the technology shocks and firms' exposure (panel A), the relationship between the magnitude of the technology shock and expected stock returns (panel B), and the differences in expected stock returns between firms in sector 1 and sector 2 (panel C). Model parameters are stated in the description of figure 2. 


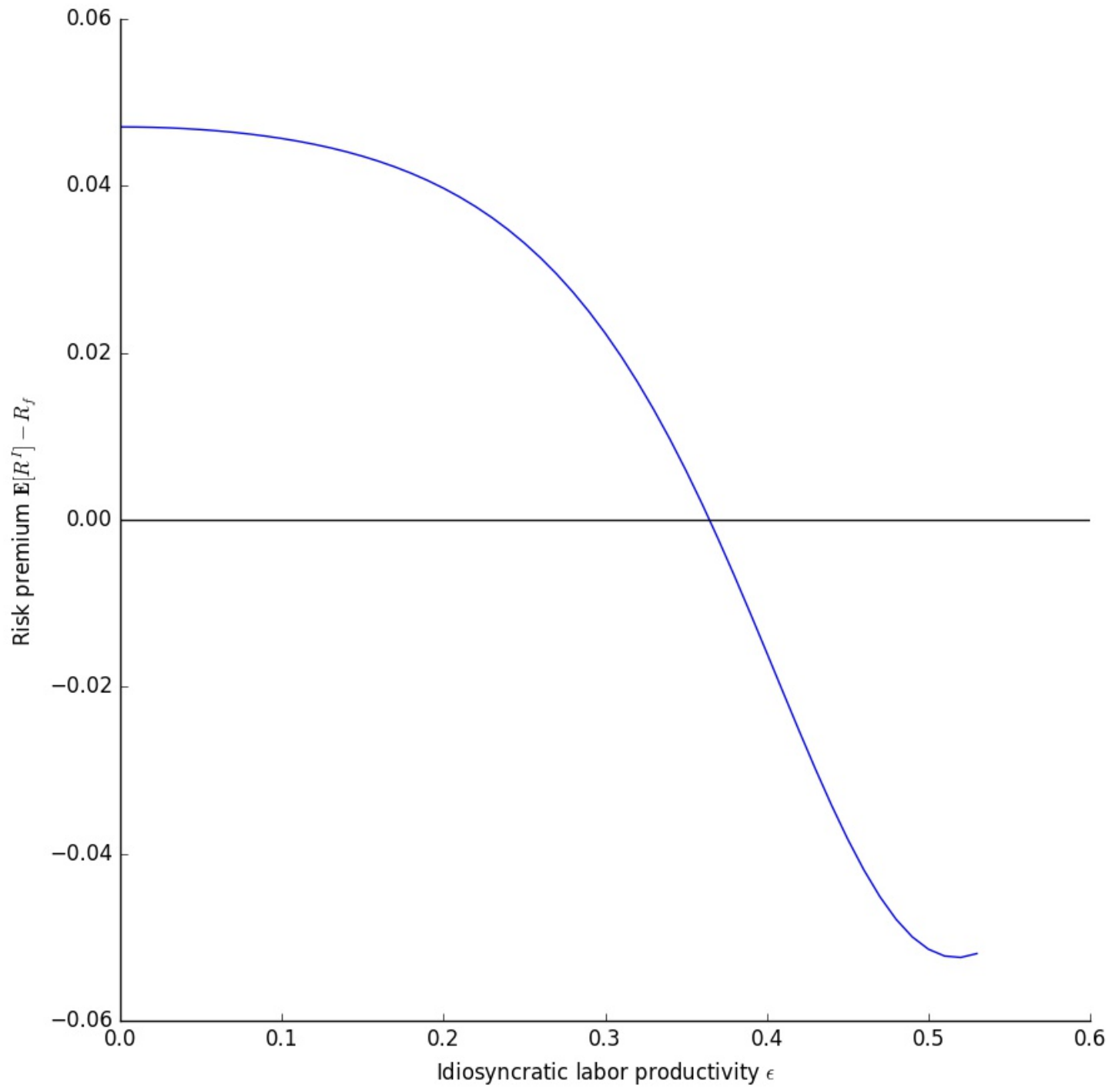

Figure 5. Idiosyncratic Labor Productivity $\epsilon$ and the Risk Premium for Technological Shocks. This figure plots the risk premium for technology shocks $\mathbf{E}\left[R^{I}\right]-R_{f}$ as a function of the idiosyncratic labor productivity risk $\epsilon . R^{I}$ is a return on an asset that has $\beta=1$ to technology shock $A_{2}$. The magnitude of the technology shock $A^{\text {High }}$ is chosen so that all firms in sector $s=1$ automate $\left(\delta^{*}\right)$. Model parameters are stated in the description of figure 2 


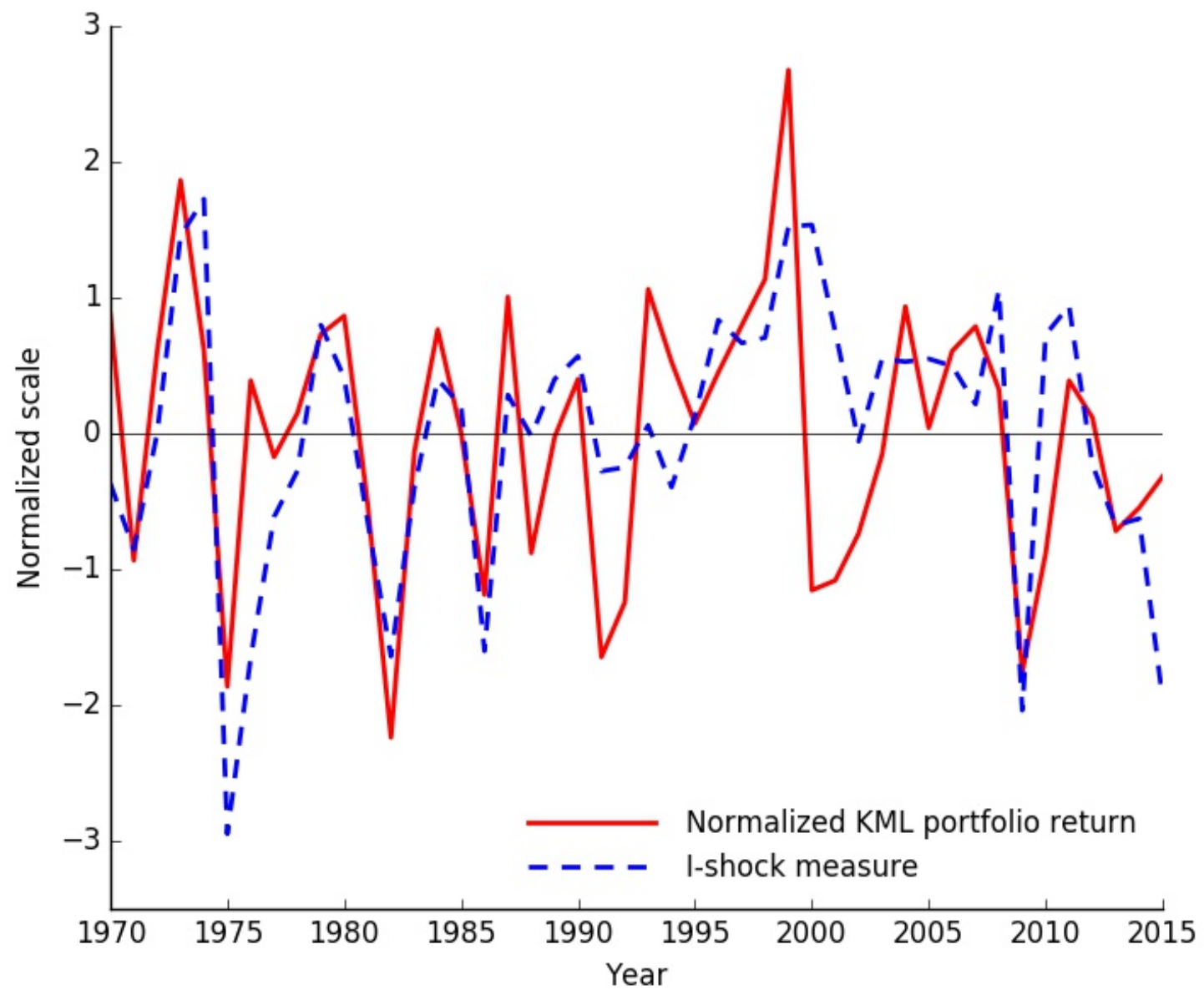

Figure 6. Technological Shocks (I-shock) and Low AP minus High AP Firms. This figure plots the I-shock measure (dashed blue line) and the annual return of the zero-cost (KML) portfolio (solid red line). The zero-cost portfolio has a long position in firms with low share of displaceable labor, i.e. the bottom quintile of firms ranked by the AP measure, and a short position in firms with high share of displaceable labor, i.e. the top quintile. The portfolio returns within the short and long position of the KML portfolio are value weighted. The KML portfolio in this figure consists of stocks from S\&P500 except for financial and utilities firms. Both time-series are plotted at annual frequency and are normalized to mean zero and standard deviation of one. The sample period is from 1970 to 2015 . 


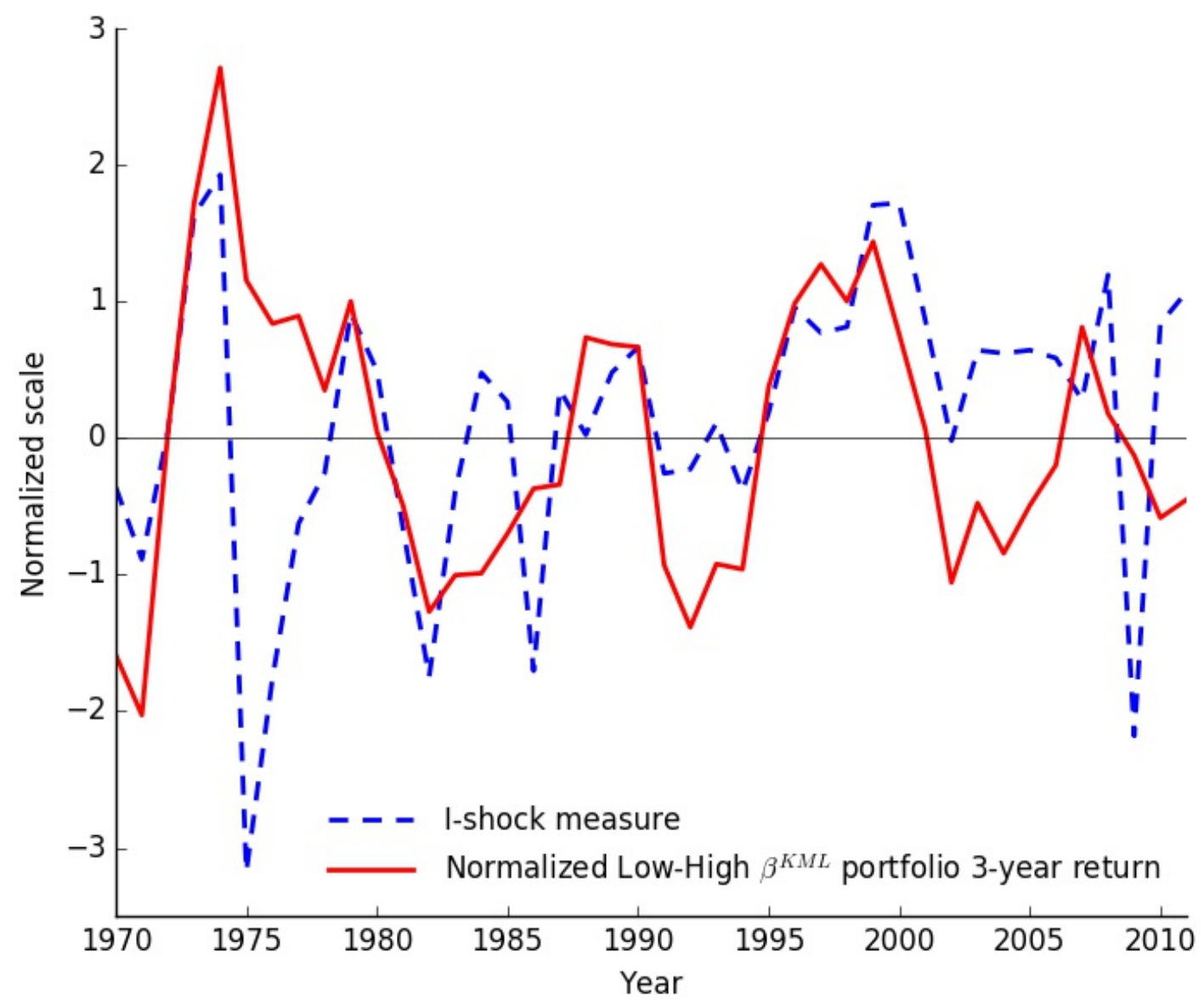

Figure 7. The I-shock Measure and Following 3-Year Cumulative Return of the LowHigh $\beta^{K M L}$ Portfolio. This figure plots the I-shock measure (dashed blue line) and the subsequent realized three-year cumulative log return of the zero-cost Low-High $\beta^{K M L}$ portfolio (solid red line). The zero-cost portfolio has a long position in stocks with low $\beta^{K M L}$ and short position in stocks with high $\beta^{K M L}$. The portfolio returns within the short and long position are value-weighted. The portfolio is rebalanced annually at the end of June. Both time-series are plotted at annual frequency and are normalized to mean zero and standard deviation of one. The sample period is from 1970 to 2015. 


\section{Table I}

\section{Summary Statistics and Variance Decomposition of the AP measure}

This table reports the summary statistics of the AP measure and its main components, $\ln \left(\frac{K}{L}\right)$ and $\frac{L^{\text {routine }}}{L^{\text {total }}}$. (-)AP denotes $\ln \left(\frac{K}{L^{\text {routine }}}\right)$ to avoid negative numbers and facilitate readability. The reported results are time-series averages of cross-sectional statistics. Panel A shows the summary statistics at the firm level and panel B at the industry level. Panel C reports the variance decomposition of the 1/AP measure and its components into within and between industry variance. The number in panel $\mathrm{C}$ denote the percentage of total variance. By construction, $\frac{L^{\text {routine }}}{L^{\text {total }}}$ has $100 \%$ variance at industry level. Industries are defined at SIC 1987 3-digit and NAICS 2002 4-digit level.

\begin{tabular}{|c|c|c|c|c|c|}
\hline & Mean & Median & St. dev. & Min & Max \\
\hline \multicolumn{6}{|c|}{ Panel A. Summary statistics at the firm level } \\
\hline$(-) \mathrm{AP}$ & 4.379 & 4.186 & 1.274 & -1.689 & 9.442 \\
\hline $\ln \left(\frac{K}{L}\right)$ & 3.363 & 3.221 & 1.156 & -2.428 & 8.142 \\
\hline \multicolumn{6}{|c|}{ Panel B. Summary statistics at the industry level } \\
\hline$(-) \mathrm{AP}$ & 4.452 & 4.229 & 1.204 & 1.191 & 8.682 \\
\hline $\ln \left(\frac{K}{L}\right)$ & 3.413 & 3.248 & 1.064 & 0.306 & 7.172 \\
\hline$\frac{L^{\text {routine }}}{L^{\text {total }}}$ & 0.407 & 0.407 & 0.187 & 0.043 & 0.814 \\
\hline \multicolumn{6}{|c|}{$\begin{array}{l}\text { Panel C. Decomposition of variance into within and between } \\
\text { industry components }\end{array}$} \\
\hline \multicolumn{4}{|c|}{$(-) \mathrm{AP}$} & $\ln \left(\frac{K}{L}\right)$ & $\frac{L^{\text {routine }}}{L^{\text {total }}}$ \\
\hline \multicolumn{3}{|c|}{ Within industries } & & 34.87 & 0 \\
\hline \multicolumn{3}{|c|}{ Between industries } & & 65.13 & 100 \\
\hline
\end{tabular}




\section{Table II \\ Technological Shocks and Investment, Employment, and Income Growth}

This table reports the results of regressing contemporaneous and future changes in investment, employment and income, panel A, and change in moments of income growth distribution, panel B, on the I-shock measure and TFP shock. The regression is of the form $\frac{1}{K+1} \sum_{k=0}^{K} y_{t+k}-y_{t+k-1}=$ $\alpha+\gamma_{I \text { shock }} \times I$ shock $k_{t}+\gamma_{T F P} \times T F P_{t}+\epsilon_{t+k}$, for time horizons $K=0,1$, and 2. Ishock $k_{t}$ is the I-shock measure representing the change in quality-adjusted relative prices of capital goods between $t-1$ and $t$. TFP $P_{t}$ is the change in aggregate productivity between $t-1$ and $t$. The regressions are estimated at annual frequency. The time period in panel A is from 1970 to 2015 and in panel B from 1978 to $2010 .{ }^{* * *}$ Significant at the 1 percent level. ${ }^{* *}$ Significant at the 5 percent level. * Significant at the 10 percent level. Source: Income, investment and employment: U.S. Bureau of Economic Analysis; Moments of income growth distribution: Guvenen et al. (2014).

\begin{tabular}{|c|c|c|c|c|c|c|c|c|c|}
\hline \multicolumn{4}{|c|}{$\begin{array}{r}\text { Panel A. Impact of technological sho } \\
\text { Investment }\end{array}$} & \multicolumn{3}{|c|}{ Employment } & \multicolumn{3}{|c|}{ Personal income } \\
\hline & $\begin{array}{c}\mathrm{t} \\
(1)\end{array}$ & $\begin{array}{c}\mathrm{t}+1 \\
(2)\end{array}$ & $\begin{array}{c}\mathrm{t}+2 \\
(3)\end{array}$ & $\begin{array}{c}t \\
(4)\end{array}$ & $\begin{array}{c}\mathrm{t}+1 \\
(5)\end{array}$ & $\begin{array}{c}\mathrm{t}+2 \\
(6)\end{array}$ & $\begin{array}{c}\mathrm{t} \\
(7)\end{array}$ & $\begin{array}{c}t+1 \\
(8)\end{array}$ & $\begin{array}{c}\mathrm{t}+2 \\
(9)\end{array}$ \\
\hline Constant & $\begin{array}{c}-0.026 \\
(0.024)\end{array}$ & $\begin{array}{c}0.038 \\
(0.028)\end{array}$ & $\begin{array}{c}0.065^{* * *} \\
(0.019)\end{array}$ & $\begin{array}{c}0.005 \\
(0.006)\end{array}$ & $\begin{array}{c}0.026^{* * *} \\
(0.009)\end{array}$ & $\begin{array}{c}0.026^{* * *} \\
(0.006)\end{array}$ & $\begin{array}{c}0.06^{* * *} \\
(0.01)\end{array}$ & $\begin{array}{c}0.122^{* * *} \\
(0.018)\end{array}$ & $\begin{array}{c}0.094^{* * *} \\
(0.014)\end{array}$ \\
\hline Ishock & $\begin{array}{c}1.296^{* * *} \\
(0.348)\end{array}$ & $\begin{array}{c}0.516 \\
(0.474)\end{array}$ & $\begin{array}{c}-0.201 \\
(0.298)\end{array}$ & $\begin{array}{c}0.081 \\
(0.063)\end{array}$ & $\begin{array}{c}-0.184^{*} \\
(0.103)\end{array}$ & $\begin{array}{c}-0.272^{* * *} \\
(0.077)\end{array}$ & $\begin{array}{c}-0.204^{*} \\
(0.113)\end{array}$ & $\begin{array}{c}-0.472^{* *} \\
(0.202)\end{array}$ & $\begin{array}{c}-0.453^{* * *} \\
(0.139)\end{array}$ \\
\hline TFP & $\begin{array}{c}2.383^{* * *} \\
(0.802)\end{array}$ & $\begin{array}{l}4.775^{* * *} \\
\quad(1.42)\end{array}$ & $\begin{array}{c}2.457^{* * *} \\
(0.732)\end{array}$ & $\begin{array}{c}0.662^{* * *} \\
(0.194)\end{array}$ & $\begin{array}{c}1.156^{* * *} \\
(0.339)\end{array}$ & $\begin{array}{c}0.748^{* * *} \\
(0.194)\end{array}$ & $\begin{array}{c}0.289 \\
(0.425)\end{array}$ & $\begin{array}{c}0.223 \\
(0.719)\end{array}$ & $\begin{array}{c}0.183 \\
(0.469)\end{array}$ \\
\hline$R^{2}$ & 41.05 & 29.2 & 20.47 & 26.3 & 25.36 & 36.16 & 7.95 & 10.12 & 18.61 \\
\hline
\end{tabular}

Panel B. Impact of technological shock on distribution of income growth

\begin{tabular}{|c|c|c|c|c|c|c|c|c|c|}
\hline & \multicolumn{3}{|c|}{ Mean } & \multicolumn{3}{|c|}{ Standard deviation } & \multicolumn{3}{|c|}{ Skewness } \\
\hline & $\mathrm{t}$ & $t+1$ & $t+2$ & $\mathrm{t}$ & $t+1$ & $t+2$ & $\mathrm{t}$ & $t+1$ & $\mathrm{t}+2$ \\
\hline \multirow[t]{2}{*}{ Constant } & $0.024^{* *}$ & $0.042^{* * *}$ & $0.018^{* *}$ & $-0.008^{* *}$ & $-0.015 * * *$ & $-0.009^{* *}$ & $0.168^{*}$ & $0.279^{* * *}$ & $0.119^{* *}$ \\
\hline & $(0.011)$ & $(0.009)$ & $(0.008)$ & $(0.004)$ & $(0.005)$ & $(0.005)$ & $(0.087)$ & $(0.088)$ & $(0.052)$ \\
\hline \multirow[t]{2}{*}{ Ishock } & $-0.524^{* *}$ & $-0.785^{* * *}$ & $-0.319^{*}$ & 0.116 & $0.253^{* *}$ & 0.156 & $-4.814^{* *}$ & $-6.545^{* * *}$ & $-2.839^{* *}$ \\
\hline & $(0.254)$ & $(0.167)$ & $(0.163)$ & $(0.104)$ & $(0.115)$ & $(0.102)$ & $(1.932)$ & $(1.575)$ & $(1.055)$ \\
\hline \multirow[t]{2}{*}{ TFP } & 0.117 & -0.487 & $-0.378^{*}$ & 0.012 & -0.094 & -0.069 & $6.594^{* *}$ & 2.247 & 0.461 \\
\hline & $(0.393)$ & $(0.361)$ & $(0.21)$ & $(0.165)$ & $(0.152)$ & $(0.103)$ & $(2.473)$ & $(2.594)$ & $(1.565)$ \\
\hline$R^{2}$ & 17.33 & 36.2 & 26.11 & 6.4 & 15.82 & 15.98 & 37.66 & 33.51 & 22.31 \\
\hline
\end{tabular}




\section{Table III \\ Correlation between the I-shock Measure and the Long-Short (KML) Portfolios Based on the between- and within-industry Automation Potential}

This table reports the correlation coefficients between the I-shock measure and the long-short portfolio (KML) constructed by the AP measure based on within or between industry variations. The long-short portfolios in the 'Between' row are constructed by ranking industries by the industrylevel average share of displaceable labor, AP. The long position consists of industries in the bottom quintile ranked by the AP measure and the short position of industries in the top quintile. The long-short portfolios in the 'Within' row are constructed by ranking individual firms by firms' deviation from the industry average share of displaceable labor. The long position consists of firms in the bottom quintile ranked deviation from industry's average AP and the short position of firms in the top quintile. Industries are defined at SIC 4-digit level in column 1, SIC 3-digit level in column 2, NAICS 6-digit level in column 3, and NAICS 5-digit level in column 4.

\begin{tabular}{lcccc}
\hline & $(1)$ & $(2)$ & $(3)$ & $(4)$ \\
\hline & SIC 4 & SIC 3 & NAICS 6 & NAICS 5 \\
Between industries & 0.586 & 0.583 & 0.545 & 0.529 \\
Within industries & 0.266 & 0.235 & 0.24 & 0.312 \\
\hline
\end{tabular}




\section{Table IV \\ Exposure of Portfolio Returns to Technological Shocks (I-shocks)}

This table reports the results from regressing portfolio annual excess returns on a constant, the I-shock measure and return factors. Regressions in panel A include a constant and the I-shock measure. The aggregate market return (CRSP value-weighted index) is added to the regressions in panel B, and the size (SMB) and value (HML) factors of Fama and French (1993) are added to the regressions in panel C. Stocks are assigned to one of five portfolios based on the share of displaceable labor, AP. Portfolios are rebalanced annually at the end of June. Portfolio returns are value-weighted. The sample period is from 1970 to 2015. Newey and West (1987) standard errors are in parentheses. ${ }^{* * *}$ Significant at the 1 percent level. ${ }^{* *}$ Significant at the 5 percent level. * Significant at the 10 percent level.

\begin{tabular}{|c|c|c|c|c|c|c|}
\hline & High AP & 2 & 3 & 4 & Low AP & $\begin{array}{c}\text { Low-High AP } \\
\text { KML }\end{array}$ \\
\hline \multicolumn{7}{|c|}{ Panel A. Exposure to I-shock measure } \\
\hline Ishock & $\begin{array}{c}-3.381^{* * *} \\
(0.952)\end{array}$ & $\begin{array}{c}-2.714^{* * *} \\
(0.685)\end{array}$ & $\begin{array}{c}-2.443^{* * *} \\
(0.811)\end{array}$ & $\begin{array}{c}-1.957^{* *} \\
(0.809)\end{array}$ & $\begin{array}{c}-1.04 \\
(0.808)\end{array}$ & $\begin{array}{c}2.341^{* * *} \\
(0.466)\end{array}$ \\
\hline$R^{2}$ & $29.19 \%$ & $28.21 \%$ & $20.53 \%$ & $15.31 \%$ & $4.43 \%$ & $30.15 \%$ \\
\hline \multicolumn{7}{|c|}{ Panel B. Exposure to I-shock measure and aggregate market } \\
\hline Ishock & $\begin{array}{c}-1.646^{* * *} \\
(0.396)\end{array}$ & $\begin{array}{c}-1.197^{* * *} \\
(0.338)\end{array}$ & $\begin{array}{c}-0.691^{* * *} \\
(0.246)\end{array}$ & $\begin{array}{l}-0.264 \\
(0.226)\end{array}$ & $\begin{array}{c}0.725^{* * *} \\
(0.258)\end{array}$ & $\begin{array}{c}2.37^{* * *} \\
(0.453)\end{array}$ \\
\hline Market & $\begin{array}{c}0.955^{* * *} \\
(0.091)\end{array}$ & $\begin{array}{c}0.835^{* * *} \\
(0.069)\end{array}$ & $\begin{array}{c}0.965^{* * *} \\
(0.036)\end{array}$ & $\begin{array}{c}0.932^{* * *} \\
(0.036)\end{array}$ & $\begin{array}{c}0.971^{* * *} \\
(0.058)\end{array}$ & $\begin{array}{c}0.016 \\
(0.119)\end{array}$ \\
\hline$R^{2}$ & $81.79 \%$ & $88.47 \%$ & $92.74 \%$ & $93.67 \%$ & $91.63 \%$ & $30.18 \%$ \\
\hline \multicolumn{7}{|c|}{$\begin{array}{l}\text { Panel C. Exposure to I-shock measure, aggregate market, } \\
\text { and factors of Fama and French (1993) }\end{array}$} \\
\hline Ishock & $\begin{array}{c}-1.365^{* * *} \\
(0.228)\end{array}$ & $\begin{array}{c}-1.068^{* * *} \\
(0.264)\end{array}$ & $\begin{array}{c}-0.751^{* * *} \\
(0.249)\end{array}$ & $\begin{array}{c}-0.386^{*} \\
(0.21)\end{array}$ & $\begin{array}{c}0.564^{* *} \\
(0.252)\end{array}$ & $\begin{array}{l}1.929^{* * *} \\
(0.314)\end{array}$ \\
\hline Market & $\begin{array}{c}0.94^{* * *} \\
(0.047)\end{array}$ & $\begin{array}{c}0.861^{* * *} \\
(0.041)\end{array}$ & $\begin{array}{c}0.934^{* * *} \\
(0.035)\end{array}$ & $\begin{array}{l}0.905^{* * *} \\
\quad(0.03)\end{array}$ & $\begin{array}{c}0.959^{* * *} \\
(0.036)\end{array}$ & $\begin{array}{c}0.02 \\
(0.059)\end{array}$ \\
\hline SMB & $\begin{array}{c}0.526^{* * *} \\
(0.098)\end{array}$ & $\begin{array}{c}0.117 \\
(0.074)\end{array}$ & $\begin{array}{c}0.014 \\
(0.085)\end{array}$ & $\begin{array}{c}-0.102^{* *} \\
(0.046)\end{array}$ & $\begin{array}{c}-0.22^{* * *} \\
(0.059)\end{array}$ & $\begin{array}{c}-0.746^{* * *} \\
(0.142)\end{array}$ \\
\hline HML & $\begin{array}{c}0.033 \\
(0.137)\end{array}$ & $\begin{array}{c}0.109 \\
(0.118)\end{array}$ & $\begin{array}{l}-0.102 \\
(0.073)\end{array}$ & $\begin{array}{l}-0.109 \\
(0.065)\end{array}$ & $\begin{array}{l}-0.079 \\
(0.082)\end{array}$ & $\begin{array}{l}-0.112 \\
(0.152)\end{array}$ \\
\hline$R^{2}$ & $89.96 \%$ & $89.62 \%$ & $93.08 \%$ & $94.7 \%$ & $94.31 \%$ & $66.84 \%$ \\
\hline
\end{tabular}




\section{Table V}

\section{Properties of Portfolios Sorted on $\beta^{K M L}$}

This table reports the results from regressing portfolio annual excess returns on a constant and the I-shock measure in panel $\mathrm{A}$ and time-series averages of additional characteristics across the stocks within each portfolio in panel B. Stocks are assigned to one of five to portfolios based on their exposure to the KML portfolio, $\beta_{i}^{K M L}$. Portfolios are rebalanced annually at the end of June. Portfolio returns are value-weighted. Newey and West (1987) standard errors are in parentheses. (-)AP is the negative of firm's displaceable labor share measured by $(-1) \times \ln \left(\frac{L^{\text {routine }}}{K}\right)$, BM is the book-to-market ratio, $\beta^{\text {market }}$ is the regression coefficient of market excess return from rolling time-series regressions of firm excess return onto market excess return and a constant, CF denotes cash flow, Lev denotes financial leverage, PCM denotes the price-to-cost margin, Profitability is the ratio of sales minus cost of goods sold, interest expenses, and selling, general, and administrative expenses to book equity, Size is the natural logarithm of the market capitalization in thousands, and Turnover is the fraction of shares traded to the total shares outstanding. The sample period is from 1975 to 2015 . ${ }^{* * *}$ Significant at the 1 percent level. ${ }^{* *}$ Significant at the 5 percent level. * Significant at the 10 percent level.

\begin{tabular}{|c|c|c|c|c|c|}
\hline & Low $\beta^{K M L}$ & 2 & 3 & 4 & High $\beta^{K M L}$ \\
\hline \multicolumn{6}{|c|}{ Panel A. Exposure to I-shock, postranking betas } \\
\hline \multirow[t]{2}{*}{ Ishock } & $-2.319^{* *}$ & $-2.495^{* * *}$ & $-1.744^{* * *}$ & $-1.701^{* * *}$ & -1.18 \\
\hline & $(1.109)$ & $(0.888)$ & $(0.606)$ & $(0.582)$ & $(0.754)$ \\
\hline$R^{2}$ & $14.22 \%$ & $25.4 \%$ & $13.05 \%$ & $12.72 \%$ & $6.32 \%$ \\
\hline \multicolumn{6}{|c|}{ Panel B. Additional properties } \\
\hline$(-) \mathrm{AP}$ & 4.047 & 4.068 & 4.099 & 4.187 & 4.623 \\
\hline $\mathrm{BM}$ & 0.677 & 0.664 & 0.668 & 0.655 & 0.619 \\
\hline$\beta^{\text {market }}$ & 1.431 & 1.166 & 1.077 & 1.052 & 1.180 \\
\hline $\mathrm{CF}$ & 0.089 & 0.095 & 0.096 & 0.094 & 0.092 \\
\hline Lev & 0.330 & 0.322 & 0.314 & 0.316 & 0.310 \\
\hline $\mathrm{PCM}$ & 0.310 & 0.321 & 0.317 & 0.319 & 0.331 \\
\hline Profitability & 0.249 & 0.256 & 0.255 & 0.247 & 0.230 \\
\hline Size & 5.576 & 5.909 & 6.063 & 6.119 & 6.240 \\
\hline Turnover & 0.109 & 0.086 & 0.080 & 0.081 & 0.101 \\
\hline
\end{tabular}




\section{Table VI \\ Mean Portfolio Returns and Alphas of Portfolios Sorted on $\beta^{K M L}$}

This table reports the time-series averages of value-weighted portfolio excess returns in panel A, equally-weighted portfolio excess returns in panel B, results of regressing monthly value-weighted portfolio excess returns on a constant and market excess return in panel $\mathrm{C}$ and results of regressing monthly value-weighted portfolio returns on a constant, market excess return, and the size (SMB) and value (HML) factors of Fama and French (1993) in panel D. Newey and West (1987) standard errors are reported in parentheses. Stocks are assigned to one of five portfolios based on their exposure to the KML portfolio, $\beta^{K M L}$, is estimated from rolling regressions of stock's monthly excess return on a constant and monthly return of the KML portfolio over the last 60 months. Portfolios are rebalanced annually at the end of June. The average excess returns and standard errors in panel A and B are annualized averages of monthly excess returns. The alpha estimates and their standard errors in panel $\mathrm{C}$ and $\mathrm{D}$ are annualized. The sample period is from 1975 to 2015. *** Significant at the 1 percent level. ${ }^{* *}$ Significant at the 5 percent level. ${ }^{*}$ Significant at the 10 percent level.

\begin{tabular}{|c|c|c|c|c|c|c|}
\hline & Low $\beta^{K M L}$ & 2 & 3 & 4 & High $\beta^{K M L}$ & $\begin{array}{c}\text { High-Low } \\
\beta^{K M L}\end{array}$ \\
\hline \multicolumn{7}{|c|}{ Panel A. Value-weighted portfolio excess return } \\
\hline Excess return & $\begin{array}{c}12.45^{* * *} \\
(3.2)\end{array}$ & $\begin{array}{c}11.54^{* * * *} \\
(2.76)\end{array}$ & $\begin{array}{c}10.03^{* * * *} \\
(2.66)\end{array}$ & $\begin{array}{c}7.45^{* * *} \\
(2.65)\end{array}$ & $\begin{array}{l}5.6^{* *} \\
(2.65)\end{array}$ & $\begin{array}{c}-6.85^{* * *} \\
(2.14)\end{array}$ \\
\hline \multicolumn{7}{|c|}{ Panel B. Equally-weighted portfolio excess return } \\
\hline Excess return & $\begin{array}{c}12.95^{* * *} \\
(3.48)\end{array}$ & $\begin{array}{c}12.57^{* * * *} \\
(3.16)\end{array}$ & $\begin{array}{c}11.1^{* * *} \\
(2.96)\end{array}$ & $\begin{array}{c}10.45^{* * *} \\
(2.94)\end{array}$ & $\begin{array}{c}8.66^{* * *} \\
(3.24)\end{array}$ & $\begin{array}{c}-4.29^{* *} \\
(1.7)\end{array}$ \\
\hline \multicolumn{7}{|c|}{ Panel C. CAPM } \\
\hline Alpha & $\begin{array}{l}2.966^{*} \\
(1.745)\end{array}$ & $\begin{array}{c}2.985 * * \\
(1.419)\end{array}$ & $\begin{array}{c}2.028^{* *} \\
(0.96)\end{array}$ & $\begin{array}{c}-0.79 \\
(0.817)\end{array}$ & $\begin{array}{c}-2.423^{* *} \\
(1.188)\end{array}$ & $\begin{array}{c}-5.389 * * \\
(2.475)\end{array}$ \\
\hline Market & $\begin{array}{c}1.16^{* * *} \\
(0.06)\end{array}$ & $\begin{array}{c}1.047^{* * *} * \\
(0.044)\end{array}$ & $\begin{array}{c}0.979 * * * \\
(0.036)\end{array}$ & $\begin{array}{c}1.009^{* * *} \\
(0.017)\end{array}$ & $\begin{array}{c}0.981^{* * *} * \\
(0.054)\end{array}$ & $\begin{array}{c}-0.179^{*} \\
(0.104)\end{array}$ \\
\hline$R^{2}$ & $78.48 \%$ & $85.02 \%$ & $86.28 \%$ & $90.22 \%$ & $80.17 \%$ & $3.56 \%$ \\
\hline \multicolumn{7}{|c|}{ Panel D. Three-factor model of Fama and French (1993) } \\
\hline Alpha & $\begin{array}{c}2.263 \\
(1.584)\end{array}$ & $\begin{array}{c}2.304^{* *} \\
(1.015)\end{array}$ & $\begin{array}{l}1.737^{*} \\
(0.968)\end{array}$ & $\begin{array}{c}-0.42 \\
(0.791)\end{array}$ & $\begin{array}{l}-1.385 \\
(0.942)\end{array}$ & $\begin{array}{l}-3.648^{*} \\
(1.989)\end{array}$ \\
\hline Market & $\begin{array}{l}1.11^{* * *} \\
(0.054)\end{array}$ & $\begin{array}{c}1.036^{* * *} \\
(0.035)\end{array}$ & $\begin{array}{c}0.989^{* * *} \\
(0.034)\end{array}$ & $\begin{array}{c}1.014^{* * *} \\
(0.015)\end{array}$ & $\begin{array}{c}0.974^{* * *} \\
(0.046)\end{array}$ & $\begin{array}{l}-0.137 \\
(0.084)\end{array}$ \\
\hline SMB & $\begin{array}{c}0.312^{* * *} \\
(0.108)\end{array}$ & $\begin{array}{c}0.144^{* * *} \\
(0.04)\end{array}$ & $\begin{array}{l}-0.001 \\
(0.041)\end{array}$ & $\begin{array}{c}-0.075^{* *} \\
(0.031)\end{array}$ & $\begin{array}{c}-0.106^{* *} \\
(0.046)\end{array}$ & $\begin{array}{c}-0.419^{* * *} \\
(0.123)\end{array}$ \\
\hline HML & $\begin{array}{l}-0.001 \\
(0.116)\end{array}$ & $\begin{array}{c}0.068 \\
(0.075)\end{array}$ & $\begin{array}{c}0.056 \\
(0.052)\end{array}$ & $\begin{array}{l}-0.038 \\
(0.039)\end{array}$ & $\begin{array}{c}-0.152^{* *} \\
(0.074)\end{array}$ & $\begin{array}{l}-0.151 \\
(0.168)\end{array}$ \\
\hline$R^{2}$ & $80.82 \%$ & $85.79 \%$ & $86.39 \%$ & $90.46 \%$ & $81.27 \%$ & $12.35 \%$ \\
\hline
\end{tabular}


Table VII

Panel Regressions of Annual Stock Returns on $\beta^{K M L}$ and Firm Characteristics

This table reports the results of regressing annual stock returns on a constant, $\beta^{K M L}$, other stocks characteristics and year fixed effect as indicated. Standard errors are clustered at the firm level and reported in parentheses. $\beta^{K M L}$ is estimated from rolling regressions of stock's monthly excess return on a constant and monthly return of the KML portfolio over the last 60 months. BM is the book-to-market equity ratio, $\beta^{\text {market }}$ is the regression coefficient of market excess return from rolling time-series regression of firm excess return onto market excess return and a constant, CF denotes cash flow, Lev denotes financial leverage, PCM denotes the price-to-cost margin, Profitability is the ratio of sales minus cost of goods sold, interest expenses, and selling, general, and administrative expenses to book equity, Size is the natural logarithm of the market capitalization in thousands, and Turnover is the fraction of shares traded to the total shares outstanding. The sample period is from 1975 to 2015 . *** Significant at the 1 percent level. ** Significant at the 5 percent level. * Significant at the 10 percent level.

\begin{tabular}{|c|c|c|c|c|c|c|c|c|c|c|c|}
\hline & $(1)$ & (2) & (3) & $(4)$ & $(5)$ & $(6)$ & $(7)$ & $(8)$ & (9) & $(10)$ & (11) \\
\hline$\beta^{K M L}$ & $\begin{array}{c}-3.829^{* * *} \\
(0.249)\end{array}$ & $\begin{array}{c}-1.599^{* * *} \\
(0.296)\end{array}$ & $\begin{array}{c}-1.531^{* * *} \\
(0.307)\end{array}$ & $\begin{array}{c}-2.032^{* * *} \\
(0.297)\end{array}$ & $\begin{array}{c}-1.544^{* * * *} \\
(0.292)\end{array}$ & $\begin{array}{c}-1.690^{* * *} \\
(0.297)\end{array}$ & $\begin{array}{c}-1.653^{* * * *} \\
(0.297)\end{array}$ & $\begin{array}{c}-1.444^{* * *} \\
(0.324)\end{array}$ & $\begin{array}{c}-1.902^{* * *} \\
(0.299)\end{array}$ & $\begin{array}{c}-1.558^{* * *} \\
(0.295)\end{array}$ & $\begin{array}{c}-2.106^{* * *} \\
(0.333)\end{array}$ \\
\hline$B M$ & & & $\begin{array}{c}1.207^{* * *} \\
(0.314)\end{array}$ & & & & & & & & $\begin{array}{c}2.005^{* * *} \\
(0.393)\end{array}$ \\
\hline Beta & & & & $\begin{array}{c}-4.728^{* * *} \\
(0.331)\end{array}$ & & & & & & & $\begin{array}{c}-2.649^{* * *} \\
(0.399)\end{array}$ \\
\hline$C F$ & & & & & $\begin{array}{c}18.39^{* * *} \\
(3.563)\end{array}$ & & & & & & $\begin{array}{l}11.01^{* *} \\
(4.736)\end{array}$ \\
\hline Lev & & & & & & $\begin{array}{c}-4.471^{* * *} \\
(0.881)\end{array}$ & & & & & $\begin{array}{c}-4.495^{* * *} \\
(1.032)\end{array}$ \\
\hline$P C M$ & & & & & & & $\begin{array}{c}3.279^{* * *} \\
(1.099)\end{array}$ & & & & $\begin{array}{l}4.033^{* * *} \\
(1.244)\end{array}$ \\
\hline Profitability & & & & & & & & $\begin{array}{l}0.397^{* *} \\
(0.162)\end{array}$ & & & $\begin{array}{l}0.360^{* *} \\
(0.148)\end{array}$ \\
\hline Size & & & & & & & & & $\begin{array}{c}0.799^{* * *} \\
(0.118)\end{array}$ & & $\begin{array}{c}0.909^{* * *} \\
(0.139)\end{array}$ \\
\hline Turnover & & & & & & & & & & $\begin{array}{c}-29.38^{* * * *} \\
(2.320)\end{array}$ & $\begin{array}{c}-23.80^{* * * *} \\
(2.576)\end{array}$ \\
\hline Year fixed effect & No & Yes & Yes & Yes & Yes & Yes & Yes & Yes & Yes & Yes & Yes \\
\hline $\mathrm{N}$ & 57959 & 57959 & 54810 & 57959 & 57906 & 57769 & 57958 & 49348 & 57959 & 57959 & 49234 \\
\hline$R^{2}$ & 0.00528 & 0.154 & 0.154 & 0.158 & 0.156 & 0.155 & 0.154 & 0.157 & 0.155 & 0.159 & 0.166 \\
\hline
\end{tabular}




\section{Table VIII \\ Mean Portfolio Returns for Conditionally Double-Sorted Portfolios}

This table reports the average excess returns for conditionally double-sorted portfolios. In the first step, I sort stocks into three baskets based on the control variable indicated in each column. In the second step, I sort stocks within each of these three baskets into three additional baskets based on $\beta^{K M L}$ resulting in nine portfolios in total. I then create three portfolios by pooling the stocks

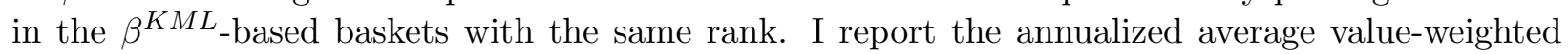
returns for portfolios with conditionally low-, medium-, and high- $\beta^{K M L}$ stocks as well as for the High-Low $\beta^{K M L}$ portfolio. Newey and West (1987) standard errors are in parentheses. $\beta^{K M L}$ is estimated from rolling regressions of stock's monthly excess return on a constant and monthly return of the KML portfolio over the last 60 months. BM is the book-to-market equity ratio, $\beta^{\text {market }}$ is the regression coefficient of market excess return from rolling time-series regression of firm excess return onto market excess return and a constant, CF denotes cash flow, Lev denotes financial leverage, PCM denotes the price-to-cost margin, Profitability is the ratio of sales minus cost of goods sold, interest expenses, and selling, general, and administrative expenses to book equity, Size is the natural logarithm of the market capitalization in thousands, and Turnover is the fraction of shares traded to the total shares outstanding. The first column shows average excess return for unconditional sorting based on $\beta^{K M L}$. The last column reports average excess return for sorting on BM conditional on Size. The sample period is from 1975 to 2015. *** Significant at the 1 percent level. ${ }^{* *}$ Significant at the 5 percent level. ${ }^{*}$ Significant at the 10 percent level.

\begin{tabular}{|c|c|c|c|c|c|c|c|c|c|c|}
\hline & $\begin{array}{c}\text { Uncond } \\
\text { (1) }\end{array}$ & $\begin{array}{l}\mathrm{BM} \\
(2)\end{array}$ & $\begin{array}{c}\beta^{\text {market }} \\
(3)\end{array}$ & (4) & $\begin{array}{l}\text { Lev } \\
\text { (5) }\end{array}$ & $\begin{array}{l}\text { PCM } \\
(6)\end{array}$ & $\begin{array}{c}\text { Profitability } \\
\text { (7) }\end{array}$ & $\begin{array}{l}\text { Size } \\
(8)\end{array}$ & $\begin{array}{c}\text { Turnover } \\
\text { (9) }\end{array}$ & $\begin{array}{c}\text { BM } \\
\text { cond } \\
\text { Size } \\
(10)\end{array}$ \\
\hline Low $\beta^{K M L}$ & 12.72 & 10.83 & 10.53 & 10.68 & 10.41 & 11.02 & 10.78 & 9.64 & 10.24 & 6.2 \\
\hline 2 & 9.56 & 7.42 & 7.26 & 7.99 & 8.38 & 7.84 & 8.43 & 7.7 & 8.39 & 7.33 \\
\hline $\operatorname{High} \beta^{K M L}$ & 6.12 & 5.6 & 5.94 & 5.44 & 5.42 & 5.66 & 5.35 & 5.43 & 5.53 & 8.35 \\
\hline High-Low $\beta^{K M L}$ & $\begin{array}{c}-6.6^{* * *} \\
(1.83)\end{array}$ & $\begin{array}{c}-5.23^{* * *} \\
(1.51)\end{array}$ & $\begin{array}{c}-4.59^{* * *} \\
(1.55)\end{array}$ & $\begin{array}{c}-5.24^{* * *} \\
(1.64)\end{array}$ & $\begin{array}{c}-5.0^{* * *} \\
(1.55)\end{array}$ & $\begin{array}{c}-5.36^{* * *} \\
(1.64)\end{array}$ & $\begin{array}{c}-5.43^{* * *} \\
(1.61)\end{array}$ & $\begin{array}{c}-4.21^{* * *} \\
(1.59)\end{array}$ & $\begin{array}{c}-4.7^{* * *} \\
(1.56)\end{array}$ & $\begin{array}{c}2.15 \\
(1.81)\end{array}$ \\
\hline
\end{tabular}




\section{Table IX \\ Long-Horizon Predictability of the Return Premium}

This table reports the results of forecasting regressions of the y-year cumulative annual log return premium of the Low-High $\beta^{K M L}$ portfolio on the I-shock measure in panel A. Panel B shows the results of forecasting regressions that include also the aggregate economic growth (GDP), a proxy for the consumption-wealth ratio (cay) of Lettau and Ludvigson (2001), and the price-earnings ratio (CAPE P/E10) of Campbell and Shiller (1988). The horizon of the cumulative log return is indicated in columns. Low-High $\beta^{K M L}$ portfolio consists of a long position in stocks with low $\beta^{K M L}$ and a short position in stocks with high $\beta^{K M L}$. The portfolio is rebalanced annually at the end of June. The portfolio returns are value-weighted. Newey and West (1987) standard errors are reported in parentheses and Hansen and Hodrick (1980) standard errors in brackets. The sample period is from 1970 to 2015 . *** Significant at the 1 percent level. ${ }^{* *}$ Significant at the 5 percent level. * Significant at the 10 percent level. Source: The data for aggregate economic growth: U.S. Bureau of Economic Analysis; the proxy for the consumption-wealth ratio: Martin Lettau's website; the price-earnings ratio: Robert Shiller's website.

\begin{tabular}{|c|c|c|c|c|c|}
\hline & $1-1$ & $1-2$ & $1-3$ & $1-4$ & $1-5$ \\
\hline \multicolumn{6}{|c|}{ Panel A. Predicting the Low-High $\beta^{K M L}$ portfolio returns by I-shock } \\
\hline \multirow[t]{3}{*}{ Constant } & 0.05 & 0.056 & 0.119 & 0.216 & 0.319 \\
\hline & $(0.041)$ & $(0.084)$ & $(0.104)$ & $(0.11)^{*}$ & $(0.116)^{* * *}$ \\
\hline & {$[0.041]$} & {$[0.091]$} & {$[0.113]$} & {$[0.117]^{*}$} & {$[0.107]^{* * *}$} \\
\hline \multirow[t]{3}{*}{ Ishock } & 0.722 & 2.413 & 2.731 & 2.474 & 2.058 \\
\hline & $(0.738)$ & $(1.334)^{*}$ & $(1.599)^{*}$ & $(1.574)$ & $(1.6)$ \\
\hline & {$[0.586]$} & {$[1.199]^{*}$} & {$[1.526]^{*}$} & {$[1.374]^{*}$} & {$[1.232]$} \\
\hline$R^{2}$ & $2.5 \%$ & $13.9 \%$ & $13.42 \%$ & $8.54 \%$ & $5.35 \%$ \\
\hline \multicolumn{6}{|c|}{$\begin{array}{l}\text { Panel B. Predicting the Low-High } \beta^{K M L} \text { portfolio returns by I-shock and } \\
\text { additional predictors }\end{array}$} \\
\hline \multirow[t]{3}{*}{ Constant } & 0.12 & 0.132 & 0.128 & 0.172 & 0.247 \\
\hline & $(0.062)^{*}$ & $(0.114)$ & $(0.152)$ & $(0.171)$ & $(0.191)$ \\
\hline & {$[0.063]^{*}$} & {$[0.132]$} & {$[0.175]$} & {$[0.182]$} & {$[0.189]$} \\
\hline \multirow[t]{3}{*}{ Ishock } & 1.327 & 3.062 & 2.822 & 2.151 & 1.544 \\
\hline & $(0.924)$ & $(1.5)^{* *}$ & $(1.615)^{*}$ & $(1.501)$ & $(1.45)$ \\
\hline & {$[0.834]$} & {$[1.307]^{* *}$} & {$[1.289]^{* *}$} & {$[0.769]^{* * *}$} & {$[0.98]$} \\
\hline \multirow[t]{3}{*}{ GDP } & -2.453 & -1.584 & -0.068 & 2.022 & 2.95 \\
\hline & $(1.257)^{*}$ & $(1.5)$ & $(1.528)$ & (1.897) & $(1.72)^{*}$ \\
\hline & {$[1.302]^{*}$} & {$[1.455]$} & {$[1.332]$} & {$[1.223]$} & {$[1.379]^{* *}$} \\
\hline \multirow[t]{3}{*}{ cay } & 0.647 & 0.594 & -0.384 & -1.955 & -3.365 \\
\hline & $(1.141)$ & $(2.013)$ & $(2.281)$ & $(2.056)$ & $(2.035)$ \\
\hline & {$[1.18]$} & {$[2.007]$} & {$[1.874]$} & {$[1.254]$} & {$[1.569]^{* *}$} \\
\hline \multirow[t]{3}{*}{ CAPE P/E10 } & -0.001 & -0.003 & 0 & 0 & 0.001 \\
\hline & $(0.003)$ & $(0.004)$ & $(0.006)$ & $(0.007)$ & $(0.007)$ \\
\hline & {$[0.002]$} & {$[0.004]$} & {$[0.007]$} & {$[0.007]$} & {$[0.008]$} \\
\hline$R^{2}$ & $14.88 \%$ & $17.9 \%$ & $13.56 \%$ & $12.26 \%$ & $13.84 \%$ \\
\hline
\end{tabular}


Table X

Firms' One-Year Response to Technological Shocks

This table reports the results of regressing firm-level percentage changes in employment, capital and capital-labor ratio in panel $\mathrm{A}$, and sales, percentage point changes in return on capital and return on equity in Panel $\mathrm{B}$, between years $t$ and $t+1$ on the I-shock measure in year $t, I$ shock $_{t}$, firm $i^{\prime} s$ exposure to technology shock in year $t$ measured by the deciles' index, $I_{i, t}^{\beta^{K M L}}$, of cross-sectionally ranked $\beta_{i, t}^{K M L}$, and their interaction term, Ishock $k_{t} I_{i, t}^{\beta^{K M L}}$. The regressions include aggregate TFP shock, $T F P_{t}$, and deterministic trend, Trend $_{t}$, as aggregate control variables and firm $i^{\prime} s$ capital, $K_{i, t}$, age, $A g e_{i, t}$, market capitalization, $S i z e_{i, t}$, lagged dependent variable for one-year horizon $t-1$ to $t$, and firm fixed effects as firm-specific control variables. Columns $\beta^{K M L} \leq$ median and $\beta^{K M L}>$ median show results of the regressions without the interaction term estimated for firms with below and above median $\beta^{K M L}$, respectively. Standard errors are clustered at SIC 4 digit industry level and reported in parentheses. The sample period is from 1975 to 2015 . *** Significant at the 1 percent level. ${ }^{* *}$ Significant at the 5 percent level. ${ }^{*}$ Significant at the 10 percent level.

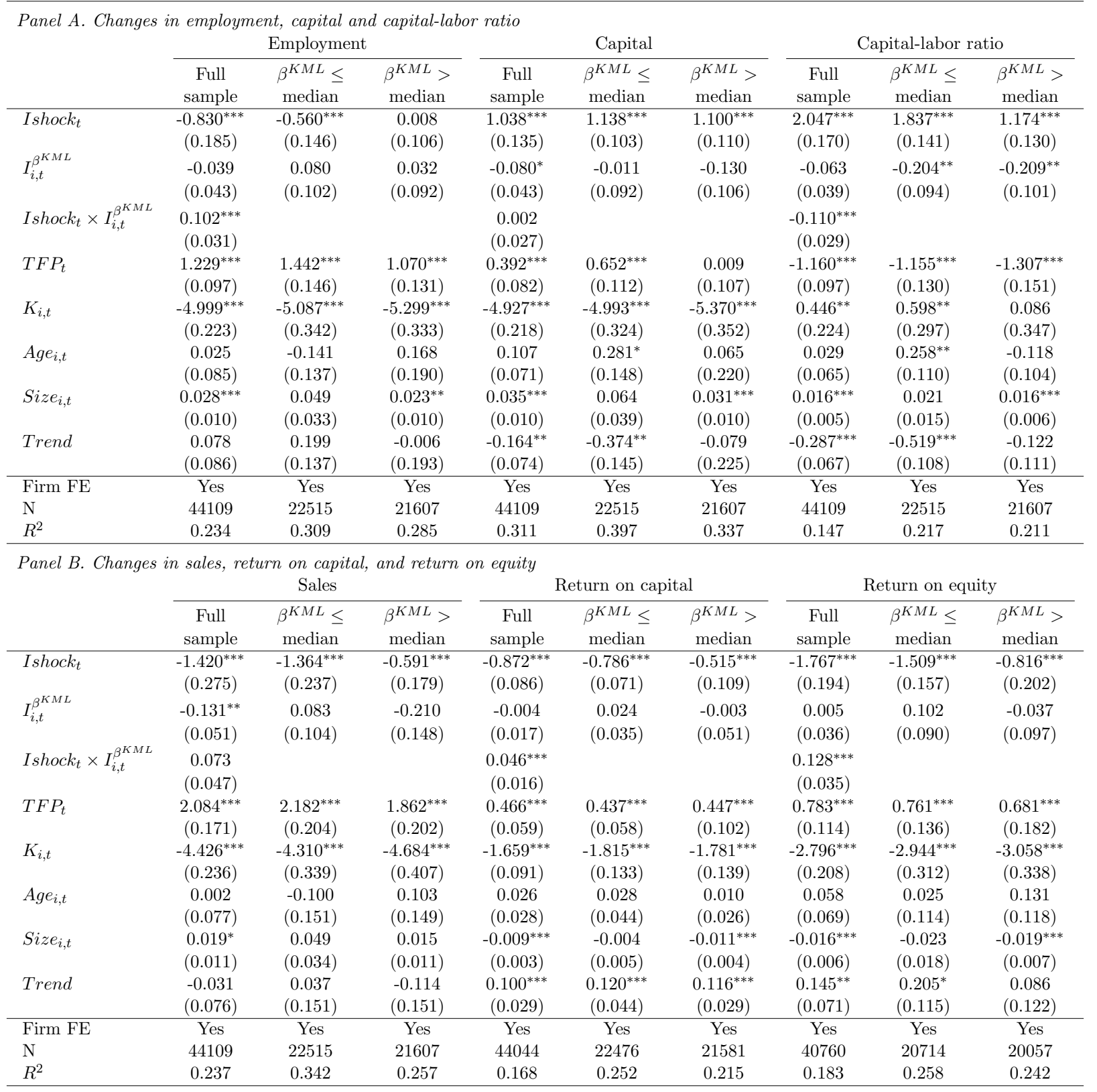




\section{Table XI}

\section{Firms' Three-Years Response to Technological Shocks, Highly Competitive versus Less Competitive Industries}

This table reports the results of regressing firm-level percentage changes in employment and capital in panel A, capital-labor ratio and sales in panel B, and percentage point changes in return on capital and return on equity in Panel $\mathrm{C}$, between years $t$ and $t+3$ on the I-shock measure in year $t, I$ shock $k_{t}$, and firm $i^{\prime} s$ exposure to technology shock in year $t$ measured by the deciles index, $I_{i, t}^{\beta^{K M L}}$, of cross-sectionally ranked $\beta_{i, t}^{K M L}$. The regressions include aggregate TFP shock, TF $P_{t}$, and deterministic trend, Trend $_{t}$, as aggregate control variables and firm $i^{\prime} s$ capital, $K_{i, t}$, age, Age $e_{i, t}$, market capitalization, $S_{i z e_{i, t}}$, lagged dependent variable for one-year horizon $t-1$ to $t$, and firm fixed effects as firm-specific control variables. The regressions are estimated for firms with below and above median $\beta^{K M L}$ in industries with high and low competition as indicated. Industries with high and low competition are industries with above and below average Herfindahl-Hirschman index of sales at the SIC 3 digit industry level. Standard errors are clustered at SIC 4 digit industry level and reported in parentheses. The sample period is from 1975 to 2015 . *** Significant at the 1 percent level. ${ }^{* *}$ Significant at the 5 percent level. ${ }^{*}$ Significant at the 10 percent level.

Panel A. Changes in employment and capital

Employment

\begin{tabular}{|c|c|c|c|c|c|c|c|c|}
\hline & \multicolumn{4}{|c|}{ 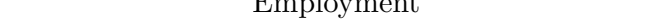 } & \\
\hline & \multicolumn{2}{|c|}{ High competition } & \multicolumn{2}{|c|}{ Low competition } & \multicolumn{2}{|c|}{ High competition } & \multicolumn{2}{|c|}{ Low competition } \\
\hline & $\begin{array}{c}\beta^{K M L} \leq \\
\text { median }\end{array}$ & $\begin{array}{c}\beta^{K M L}> \\
\text { median }\end{array}$ & $\begin{array}{c}\beta^{K M L} \leq \\
\text { median }\end{array}$ & $\begin{array}{c}\beta^{K M L}> \\
\text { median }\end{array}$ & $\begin{array}{c}\beta^{K M L} \leq \\
\text { median }\end{array}$ & $\begin{array}{c}\beta^{K M L}> \\
\text { median }\end{array}$ & $\begin{array}{c}\beta^{K M L} \leq \\
\text { median }\end{array}$ & $\begin{array}{c}\beta^{K M L}> \\
\text { median }\end{array}$ \\
\hline Ishock $_{t}$ & $\begin{array}{c}-2.810^{* * *} \\
(0.454)\end{array}$ & $\begin{array}{c}-1.730^{* * *} \\
(0.383)\end{array}$ & $\begin{array}{c}-2.595^{* * *} \\
(0.333)\end{array}$ & $\begin{array}{c}-2.196^{* * *} \\
(0.297)\end{array}$ & $\begin{array}{c}0.983^{* *} \\
(0.398)\end{array}$ & $\begin{array}{c}1.281^{* * *} \\
(0.380)\end{array}$ & $\begin{array}{c}0.841^{* * *} \\
(0.315)\end{array}$ & $\begin{array}{c}0.538^{*} \\
(0.283)\end{array}$ \\
\hline$I_{i, t}^{\beta^{K M L}}$ & $\begin{array}{l}-0.409 \\
(0.346)\end{array}$ & $\begin{array}{c}0.203 \\
(0.261)\end{array}$ & $\begin{array}{c}0.202 \\
(0.318)\end{array}$ & $\begin{array}{c}0.183 \\
(0.327)\end{array}$ & $\begin{array}{c}-0.590^{*} \\
(0.329)\end{array}$ & $\begin{array}{l}-0.018 \\
(0.397)\end{array}$ & $\begin{array}{c}0.184 \\
(0.305)\end{array}$ & $\begin{array}{c}-0.239 \\
(0.337)\end{array}$ \\
\hline Controls & Yes & Yes & Yes & Yes & Yes & Yes & Yes & Yes \\
\hline Firm FE & Yes & Yes & Yes & Yes & Yes & Yes & Yes & Yes \\
\hline $\mathrm{N}$ & 8139 & 9785 & 11672 & 9647 & 8135 & 9782 & 11667 & 9646 \\
\hline$R^{2}$ & 0.593 & 0.544 & 0.547 & 0.548 & 0.648 & 0.557 & 0.600 & 0.551 \\
\hline
\end{tabular}

Panel B. Changes in capital-labor ratio and sales Capital-labor ratio

\begin{tabular}{|c|c|c|c|}
\hline \multicolumn{2}{|c|}{ High competition } & \multicolumn{2}{|c|}{ Low competition } \\
\hline $\begin{array}{c}\beta^{K M L} \leq \\
\text { median }\end{array}$ & $\begin{array}{c}\beta^{K M L}> \\
\text { median }\end{array}$ & $\begin{array}{c}\beta^{K M L} \leq \\
\text { median }\end{array}$ & $\begin{array}{c}\beta^{K M L}> \\
\text { median }\end{array}$ \\
\hline
\end{tabular}

\begin{tabular}{lcccccccc} 
& median & median & median & median & median & median & median & median \\
\hline Ishock & $4.210^{* * *}$ & $3.398^{* * *}$ & $3.693^{* * *}$ & $2.711^{* * *}$ & $-3.410^{* * *}$ & $-2.800^{* * *}$ & $-3.039^{* * *}$ & $-2.743^{* * *}$ \\
& $(0.557)$ & $(0.360)$ & $(0.327)$ & $(0.349)$ & $(0.642)$ & $(0.565)$ & $(0.428)$ & $(0.365)$ \\
$I_{i, t}^{\beta^{K M L}}$ & -0.175 & -0.241 & -0.161 & $-0.531^{*}$ & -0.531 & -0.558 & -0.192 & -0.283 \\
& $(0.344)$ & $(0.338)$ & $(0.296)$ & $(0.319)$ & $(0.414)$ & $(0.534)$ & $(0.333)$ & $(0.374)$ \\
\hline Controls & Yes & Yes & Yes & Yes & Yes & Yes & Yes & Yes \\
Firm FE & Yes & Yes & Yes & Yes & Yes & Yes & Yes & Yes \\
$\mathrm{N}$ & 8135 & 9782 & 11667 & 9646 & 8138 & 9782 & 11671 & 9644 \\
$R^{2}$ & 0.463 & 0.446 & 0.422 & 0.433 & 0.586 & 0.488 & 0.548 & 0.542 \\
\hline
\end{tabular}

Panel C. Changes in return on capital and return on equity Return on capital

\begin{tabular}{|c|c|c|c|c|c|c|c|c|}
\hline & \multirow{2}{*}{\multicolumn{2}{|c|}{ High competition }} & \multirow{2}{*}{\multicolumn{2}{|c|}{ Low competition }} & \multirow{2}{*}{\multicolumn{2}{|c|}{ High competition }} & \multirow{2}{*}{\multicolumn{2}{|c|}{ Low competition }} \\
\hline & & & & & & & & \\
\hline & $\begin{array}{c}\beta^{K M L} \leq \\
\text { median }\end{array}$ & $\begin{array}{c}\beta^{K M L}> \\
\text { median }\end{array}$ & $\begin{array}{c}\beta^{K M L} \leq \\
\text { median }\end{array}$ & $\begin{array}{c}\beta^{K M L}> \\
\text { median }\end{array}$ & $\begin{array}{c}\beta^{K M L} \leq \\
\text { median }\end{array}$ & $\begin{array}{c}\beta^{K M L}> \\
\text { median }\end{array}$ & $\begin{array}{c}\beta^{K M L} \leq \\
\text { median }\end{array}$ & $\begin{array}{l}\beta^{K M L}> \\
\text { median }\end{array}$ \\
\hline Ishock $_{t}$ & $\begin{array}{c}-1.289^{* * *} \\
(0.141)\end{array}$ & $\begin{array}{c}-1.016^{* * *} \\
(0.249)\end{array}$ & $\begin{array}{c}-0.932^{* * *} \\
(0.102)\end{array}$ & $\begin{array}{c}-0.541^{* * *} \\
(0.093)\end{array}$ & $\begin{array}{c}-2.431^{* * *} \\
(0.319)\end{array}$ & $\begin{array}{c}-1.911^{* * *} \\
(0.448)\end{array}$ & $\begin{array}{c}-1.842^{\text {*** }} \\
(0.265)\end{array}$ & $\begin{array}{c}-0.797^{* * *} \\
(0.226)\end{array}$ \\
\hline$I_{i, t}^{\beta^{K M L}}$ & $\begin{array}{c}-0.233^{* *} \\
(0.112)\end{array}$ & $\begin{array}{c}0.052 \\
(0.134)\end{array}$ & $\begin{array}{l}-0.058 \\
(0.080)\end{array}$ & $\begin{array}{c}0.043 \\
(0.110)\end{array}$ & $\begin{array}{l}-0.330 \\
(0.273)\end{array}$ & $\begin{array}{c}0.130 \\
(0.275)\end{array}$ & $\begin{array}{l}-0.005 \\
(0.215)\end{array}$ & $\begin{array}{l}-0.134 \\
(0.264)\end{array}$ \\
\hline Controls & Yes & Yes & Yes & Yes & Yes & Yes & Yes & Yes \\
\hline Firm FE & Yes & Yes & Yes & Yes & Yes & Yes & Yes & Yes \\
\hline $\mathrm{N}$ & 8136 & 9777 & 11650 & 9634 & 7373 & 8865 & 10417 & 8731 \\
\hline$R^{2}$ & 0.436 & 0.384 & 0.369 & 0.405 & 0.447 & 0.414 & 0.368 & 0.445 \\
\hline
\end{tabular}

